\title{
Global modelling of secondary organic aerosol in the troposphere: a sensitivity analysis
}

\author{
K. Tsigaridis and M. Kanakidou \\ Environmental Chemical Processes Laboratory, Department of Chemistry, University of Crete, POBox 1470, 71409, \\ Heraklion, Crete, Greece \\ Received: 12 March 2003 - Published in Atmos. Chem. Phys. Discuss.: 2 June 2003 \\ Revised: 6 October 2003 - Accepted: 8 October 2003 - Published: 31 October 2003
}

\begin{abstract}
A global 3-dimensional chemistry/transport model able to describe $\mathrm{O}_{3}, \mathrm{NO}_{\mathrm{x}}$, Volatile Organic Compounds (VOC), sulphur and $\mathrm{NH}_{3}$ chemistry has been extended to simulate the temporal and spatial distribution of primary and secondary carbonaceous aerosols in the troposphere focusing on Secondary Organic Aerosol (SOA) formation. A number of global simulations have been performed to determine a possible range of annual global SOA production and investigate uncertainties associated with the model results. The studied uncertainties in the SOA budget have been evaluated to be in decreasing importance: the potentially irreversible sticking of the semi-volatile compounds on aerosols, the enthalpy of vaporization of these compounds, the partitioning of SOA on non-carbonaceous aerosols, the conversion of aerosols from hydrophobic to hydrophilic, the emissions of primary carbonaceous aerosols, the chemical fate of the first generation products and finally the activity coefficient of the condensable species. The large uncertainties associated with the emissions of VOC and the adopted simplification of chemistry have not been investigated in this study. Although not all sources of uncertainties have been investigated, according to our calculations, the above factors within the experimental range of variations could result to an overall uncertainty of about a factor of 20 in the global SOA budget. The global annual SOA production from biogenic VOC might range from 2.5 to $44.5 \mathrm{Tg}$ of organic matter per year, whereas that from anthropogenic VOC ranges from 0.05 to $2.62 \mathrm{Tg}$ of organic matter per year. These estimates can be considered as a lower limit, since partitioning on coarse particles like nitrate, dust or sea-salt, together with the partitioning and the dissociation of the semi-volatile products in aerosol water has been neglected. Comparison of model results to observations, where available, shows a better agreement for the upper budget estimates than for the lower ones.
\end{abstract}

Correspondence to: M. Kanakidou

(mariak@chemistry.uoc.gr)

\section{Introduction}

Atmospheric aerosols act as substrates for heterogeneous reactions and affect tropospheric chemistry (Dentener and Crutzen, 1993). Aerosols can also back scatter or absorb solar radiation modifying therefore the radiative state of the atmosphere (IPCC, 2001). Black carbon aerosols are heating the atmosphere by absorption of solar radiation, whereas the other aerosol constituents like organic aerosols are cooling the Earth's atmosphere. Due to their longer lifetimes than larger particles, fine aerosols are transported far from their source regions and are thus expected to have stronger climatic impact than larger particles. The $\mathrm{PM}_{2.5}$ fraction of them can also damage human health (Jones, 1999; Harrison and Yin, 2000). Hydrophilic aerosols can act as condensation nuclei $(\mathrm{CN})$ and even cloud condensation nuclei $(\mathrm{CCN})$, having thus an indirect climatic effect by modification of cloud properties (Novakov and Penner, 1993; Novakov and Corrigan, 1996). Organic material significantly contributes to the total fine aerosols by $\sim 20-50 \%$ at continental mid-latitudes (Saxena and Hildemann, 1996) and as high as 90\% in tropical forested areas (Andreae and Crutzen, 1997; Talbot et al., 1988, 1990; Artaxo et al., 1988, 1990). A substantial fraction of the organic component of atmospheric particles consists of water-soluble, possibly multifunctional compounds (Saxena and Hildemann, 1996; Facchini et al., 1999).

Andreae and Crutzen (1997) have suggested that the production of organic aerosols from the oxidation of biogenic organic compounds might ranges from 30 to $270 \mathrm{Tg} \mathrm{y}^{-1}$ and thus can be comparable in magnitude to the production of biogenic and anthropogenic sulphate aerosols (Pandis et al., 1992). Laboratory studies have shown that mainly ozonolysis, and to a smaller extent oxidation by $\mathrm{OH}$ and $\mathrm{NO}_{3}$ radicals of several biogenic compounds like $\alpha$ - and $\beta$-pinene produces organic substances, which can condense onto particulate phase (Hoffmann et al., 1997; Griffin et al., 1999a; Christoffersen et al., 1998). Aromatic compounds emitted from human activities can also contribute to the chemical formation of organic particulate matter (Odum et al., 
1997). Griffin et al. (1999b) performed an exploratory study of the present-day Secondary Organic Aerosol (SOA) formation from the oxidation of biogenic Volatile Organic Compounds (VOC) and estimated a global production of SOA of $13-24 \mathrm{Tg} \mathrm{y}^{-1}$. Kanakidou et al. (2000) calculated that this source of SOA has increased from $17-28 \mathrm{Tg} \mathrm{y}^{-1}$ in preindustrial times to $61-79 \mathrm{Tg}^{-1}$ at present. This 3-4-fold enhancement of the formation of organic aerosol from biogenic VOC has been attributed to an increase in ozone and primary organic aerosol from anthropogenic sources. Recently, Chung and Seinfeld (2002) re-evaluated the present-day SOA formation at $11.2 \mathrm{Tg}^{-1}$ whereas Derwent et al. (2003) estimated a higher global SOA production of $63 \mathrm{Tg}^{-1}$.

Knowledge on the formation and properties of SOA and their spatial and temporal variability is far from being satisfactory, although it is needed to evaluate their environmental impact. Therefore, a careful identification of the critical gaps in our knowledge is needed to allow further research to highlight the aerosol impact on chemistry and climate. In this perspective, the present study focuses on the estimate of the mass distribution of SOA and the identification of physicochemical processes that have not been satisfactorily addressed in previous studies and are shown to be critical for these calculations. It also addresses the importance of anthropogenic versus the natural component of SOA.

\section{Model description}

The model used for the present study is the well-documented off-line chemical transport model TM3 (Houweling et al., 1998; Dentener et al., 1999; Jeuken et al., 2001). This model version has a horizontal resolution of $3.75^{\circ} \times 5^{\circ}$ in latitude and longitude, and 19 vertical hybrid layers from the surface to $10 \mathrm{hPa}$. Roughly, 5 layers are located in the boundary layer, 8 in the free troposphere and 6 in the stratosphere. The model's input meteorology varies every $6 \mathrm{~h}$ and comes from the ECMWF ERA15 re-analysis data-archive for the year 1990 (Gibson et al., 1997; http://www.ecmwf.int/data/ $\mathrm{era} / \mathrm{html})$.

\subsection{Emissions}

For the biogenic VOC emissions, the Global Emission Inventory Activity (GEIA) database (Guenther et al., 1995) and the Emission Database for Global Atmospheric Research (EDGAR) version 2.0 database (Olivier et al., 1996), both for the year 1990 have been adopted.

According to the GEIA database (Guenther et al., 1995) about $127 \mathrm{Tg} \mathrm{C}\left(1 \mathrm{Tg}=10^{12} \mathrm{~g}\right)$ of monoterpenes are being emitted annually in the atmosphere. Other Reactive Volatile Organic Compounds (ORVOC) are being emitted by about $260 \mathrm{Tg} \mathrm{Cy}^{-1}$. $32 \%$ of them are assumed to be able to produce particles (Griffin et al., 1999b). Note however that this percentage is highly uncertain.
The emissions of aromatic hydrocarbons adopted here (EDGAR database; Olivier et al., 1996) consist of $6.7 \mathrm{Tg} \mathrm{y}^{-1}$ of toluene, $4.5 \mathrm{Tg} \mathrm{y}^{-1}$ of xylene, $0.8 \mathrm{Tg} \mathrm{y}^{-1}$ of trimethylbenzene and $3.8 \mathrm{Tg} \mathrm{y}^{-1}$ of other aromatics. Primary emissions of carbonaceous aerosols from fossil fuel are taken from Cooke et al. (1999) and consist of $5.1 \mathrm{Tg} \mathrm{y}^{-1}$ Black Carbon (BC) and 7.0 $\mathrm{Tg} \mathrm{y}^{-1}$ Organic Carbon (OC) for the primary organic aerosol (POA). For the biomass burning primary emissions of carbonaceous aerosols from tropical forests we have adopted the Cooke and Wilson (1996) estimate of $6.0 \mathrm{Tg} \mathrm{y}^{-1}$ for BC, while for POA we use an annual flux of $12.5 \mathrm{Tg} \mathrm{OC}^{-1}$ that results from the fossil fuel to biomass burning emission ratio given by Liousse et al. (1996) estimates, which was applied to Cooke et al. (1999) inventory. Temperate and boreal forests emit annually $2.9 \mathrm{Tg} \mathrm{BC}$ and $6.1 \mathrm{Tg} \mathrm{OC}$, by assuming that POA emissions are $12.3 \%$ of the temperate and boreal $\mathrm{CO}$ emissions, whereas $\mathrm{BC}$ is $5.9 \%$. In the case of POA, $50 \%$ of the emitted particles are assumed to be hydrophilic; in the case of BC, $20 \%$ of the total emissions are assumed hydrophilic (Cooke et al., 1999). In our model, these primary particles serve as pre-existing aerosol for the condensation of the chemically formed low volatility compounds, both from biogenic and anthropogenic hydrocarbons.

\subsection{Gas-phase chemistry}

The model uses a modified version of the Carbon Bond Mechanism 4 (CBM-4) chemical mechanism (Gery et al., 1989) to simulate global atmospheric chemistry as described in detail by Houweling et al. (1998), together with sulphur and ammonia chemistry (Dentener et al., 1999; Jeuken et al., 2001). For the present study, reactions of terpenes and aromatics have been included to affect both gas-phase chemistry and aerosol production. The $\alpha$ - and $\beta$-pinene represent the two biogenic SOA precursor VOC (Kanakidou et al., 2000), while toluene and xylene represent the two anthropogenically emitted aromatic compounds that form SOA (Odum et al., 1997). This lumping is justified by the missing knowledge on the molecular composition of the biogenic and anthropogenic organic emissions and their fate, together with the enormous number of compounds present in the SOA. The lack of data on the gas-phase removal parameters and on the SOA formation yields for most of the organic substances, and on their oxidation products is also implying the lumping of the atmospheric precursors of SOA. Similar approaches with different number of surrogate compounds have been used in previous studies (Griffin et al., 1999b; Kanakidou et al., 2000; Chung and Seinfeld, 2002; Derwent et al., 2003).

A two-product model approximation, which has been shown to be the simplest way to efficiently represent aerosol formation both from biogenic (Hoffmann et al., 1997) and aromatic VOC (Odum et al., 1997), is being used to represent SOA formation on line with the VOC gas-phase:

VOC + oxidant $\rightarrow a_{1} P_{1}+a_{2} P_{2}+$ high volatility products, (1) 
where $a_{i}$ is the mass-based stoicheiometric coefficient of the low volatility product $P_{i}$ that partitions between the gas and particulate phase with a partitioning coefficient $K_{i}$.

$P_{i}$ can further oxidize to gas-phase high-volatility products and second generation low volatility surrogate compounds $B_{i}$. This oxidation chain can continue until either full oxidation (down to $\mathrm{CO}, \mathrm{CO}_{2}$, etc.) or removal of the gaseous or/and the aerosol phase species from the system by wet and dry deposition. As a first approximation, and because the oxidation pathways and products of the second generation species are almost totally unknown, we assume that the second generation products considered only in case S1.3 are stable enough to have slow oxidation rates in the gas-phase. This assumption is being supported by the fact that the second generation products $\left(B_{i}\right)$ are expected to have more functional groups than the first generation products $\left(P_{i}\right)$ and thus to be enough low-volatile to reside most of their lifetime in the particulate phase. Therefore, in this sensitivity study discussed in Sect. 3.4, all biogenic first generation semi-volatile products are considered to oxidize down to similar bulk species $B_{b}$, while the anthropogenic ones oxidize to $B_{a}$. These species $\left(B_{a}, B_{b}\right)$ are not further oxidized, and are removed from the atmosphere only by wet and dry deposition. Note however that possible reactions of $P_{i}$ and $B_{i}$ products in aerosols leading to modification of the chemical composition and the mass of the aerosol have been neglected in the present study due to missing knowledge.

For carbon balance purposes the following mass-based stoicheiometric reactions are taken into account, by assuming that the products of biogenic VOC that are able to partition between gas and aerosol phase are similar to known terpene products (Christoffersen et al., 1998; Calogirou et al., 1999; Cocker III et al., 2001a):

$$
\begin{aligned}
& \alpha \text {-pinene }+\mathrm{O}_{3} \rightarrow a_{1}\left(\alpha-\text { pin- } P_{1}\right)+ \\
& a_{2}\left(\alpha-\text { pin }-P_{2}\right)+2^{*}\left(X-a_{1}-a_{2}\right)\left(\mathrm{RO}_{2}\right) \\
& \beta-\text { pinene }+\mathrm{O}_{3} \rightarrow a_{1}\left(\beta-\text { pin }-P_{1}+\mathrm{HCHO}\right) \\
& +a_{2}\left(\beta-\text { pin }-P_{2}+\mathrm{HCHO}\right)+2^{*}\left(X-a_{1}-a_{2}\right)\left(\mathrm{RO}_{2}\right) \\
& \alpha-\text { pin- } P_{1}+\text { oxidants } \rightarrow \mathrm{ALD} 2+B_{b} \\
& \alpha-\text { pin- } P_{2}+\text { oxidants } \rightarrow \mathrm{ALD} 2+B_{b} \\
& \beta-\text { pin }-P_{1}+\text { oxidants } \rightarrow \mathrm{HCHO}+B_{b} \\
& \beta-\text { pin }-P_{2}+\text { oxidants } \rightarrow \mathrm{HCHO}+B_{b},
\end{aligned}
$$

where $\mathrm{RO}_{2}$ is further treated in CBM4 as the corresponding radical formed during isoprene oxidation and ALD2 is a lumped aldehyde product as in the original CBM4 mechanism (Gery et al, 1989; Houweling et al., 1998). X denotes the ratio of the molecular weight of the parent VOC to the molecular weight of the condensable products. The factor 2 applies to the carbon balance conservation. Reactions (4), (5), (6) and (7) are considered only for the sensitivity study shown in Sect. 3.4. The reactions of biogenic VOC with $\mathrm{OH}$ and $\mathrm{NO}_{3}$ radicals are considered, but any particulate matter formation from these reactions is neglected in the present study. This assumption is not expected to be critical for the outcome of the study, since it is known that low volatile compounds are formed mainly from $\mathrm{O}_{3}$ reactions with biogenic VOC (Hoffmann et al., 1997). For simplicity, these $\mathrm{OH}$ and $\mathrm{NO}_{3}$ reactions are assumed to exclusively produce $\mathrm{RO}_{2}$ radicals that follow the isoprene oxidation chain. This assumption needs to be improved in the future.

A similar approach is followed for aromatic hydrocarbons, by assuming that the products that are able to partition are similar to known semi-volatile compounds (Forstner et al., 1997; Cocker III et al., 2001b):

$$
\begin{aligned}
& \text { toluene }+\mathrm{OH} \text { and } \mathrm{O}_{3} \rightarrow a_{1}\left(\text { tol }-P_{1}\right)+ \\
& \left.a_{2} \text { (tol }-P_{2}+\text { Methylglyoxal }\right)+7^{*}\left(X-a_{1}-a_{2}\right) \mathrm{PAR} \\
& \text { xylene }+\mathrm{OH} \text { and } \mathrm{O}_{3} \rightarrow a_{1}\left(\mathrm{xyl}-P_{1}\right)+a_{2}\left(\mathrm{xyl}-P_{2}\right. \\
& + \text { Methylglyoxal }+\mathrm{PAR})+8^{*}\left(X-a_{1}-a_{2}\right) \mathrm{PAR} \\
& \text { tol- } P_{1}+\text { oxidants } \rightarrow B_{a} \\
& \text { tol- } P_{2}+\text { oxidants } \rightarrow B_{a} \\
& \text { xyl }-P_{1}+\text { oxidants } \rightarrow B_{a} \\
& \text { xyl- } P_{2}+\text { oxidants } \rightarrow B_{a},
\end{aligned}
$$

where PAR is paraffinic carbon as in the original CBM4 mechanism (Gery et al., 1989, Houweling et al., 1998). The factors 7 and 8 apply to the carbon balance conservation. Reactions (10), (11), (12) and (13) are considered only for sensitivity study shown in Sect. 3.4. The reactions of aromatics with $\mathrm{NO}_{3}$ radicals are considered producing only high volatility products represented in the model by appropriate number of PAR.

Note that the chemical lumping of VOC forming SOA precursors and their products is a source of large uncertainties (Pun et al., 2003) that requires systematic evaluation in the future on the basis of targeted experiments. Unfortunately, all requested information to evaluate the SOA formation parameterization in our model against chamber experiments is not available in the literature. Only the full set of experimental data from chamber experiments with time evolution of gaseous and particulate compounds can allow evaluation of both the gas and particulate chemistry in the model. The time evolution of the oxidant levels that deplete the VOC precursor molecules of the VOC levels and of the aerosol mass in the chamber is the minimum prerequisite for evaluation of the aerosol module.

The adopted rates for the reactions (2)-(13) are shown in Table 1.

\subsection{Aerosol formation - factors of uncertainty}

Assuming an equilibrium partitioning into an absorptive organic matter phase (Pankow, 1994a; Pankow, 1994b; Odum 
Table 1. Temperature dependant reaction rates of particle precursor VOC (biogenic and anthropogenic) with $\mathrm{OH}, \mathrm{O}_{3}$ and $\mathrm{NO}_{3}$ used in the model. $P_{1}, P_{2}$ are the first generation products of the corresponding VOC

\begin{tabular}{ccccccc}
\hline & $\mathrm{OH}$ & \multicolumn{2}{c}{$\mathrm{O}_{3}$} & \multicolumn{2}{c}{$\mathrm{NO}_{3}$} \\
& $\mathrm{~A}$ & $\mathrm{~B}$ & $\mathrm{~A}$ & $\mathrm{~B}$ & $\mathrm{~A}$ & $\mathrm{~B}$ \\
\hline$\alpha$-pinene & $1.21 \mathrm{e}-11$ & 444 & $1.01 \mathrm{e}-15$ & -732 & $3.15 \mathrm{e}-13^{a}$ & $841^{a}$ \\
$\beta$-pinene & $2.38 \mathrm{e}-11$ & 357 & $1.5 \mathrm{e}-17$ & - & $1.6 \mathrm{e}-10^{a}$ & $-1248^{a}$ \\
toluene $^{b}$ & $5.96 \mathrm{e}-12$ & - & $2.34 \mathrm{e}-12$ & -6694 & $6.8 \mathrm{e}-17$ & - \\
xylene $^{b}$ & $1.72 \mathrm{e}-11^{c}$ & - & $d$ & $d$ & $3.54 \mathrm{e}-16 \mathrm{c}$ & - \\
$\alpha$-pin- $P_{1}^{e}$ & $4.28 \mathrm{e}-12$ & - & 0 & - & 0 & - \\
$\alpha$-pin- $P_{2}^{f}$ & $9.3 \mathrm{e}-11$ & - & $8,9 \mathrm{e}-20$ & - & $5.4 \mathrm{e}-14$ & - \\
$\beta$-pin- $P_{1}^{g}$ & $3.03 \mathrm{e}-12$ & - & 0 & - & 0 & - \\
$\beta$-pin- $P_{2}^{h}$ & $1.7 \mathrm{e}-11$ & - & $5.0 \mathrm{e}-21$ & - & $1.1 \mathrm{e}-15$ & - \\
tol- $P_{1}$ & $i$ & - & 0 & - & $i$ & - \\
tol- $P_{2}$ & $i$ & - & 0 & - & $i$ & - \\
xyl- $P_{1}$ & $j$ & - & 0 & - & $j$ & - \\
xyl- $P_{2}$ & $j$ & - & 0 & - & $j$ & - \\
\hline
\end{tabular}

$K=A * \exp (B / T)$, where $T$ is the temperature in Kelvin. Taken from Atkinson (1997) unless noted differently.

-: No temperature dependence.

${ }^{a}$ Martnez et al. (1998).

${ }^{b}$ Atkinson (1994).

${ }^{c}$ Average of ortho-, meta- and para-isomers.

$d$ Average of temperature dependence for ortho-, meta- and para-isomers: $(2.4 \mathrm{E}-13 \exp (-5586 / \mathrm{T})+5.37 \mathrm{E}-13$ exp $(-6039 / \mathrm{T})+1.91 \mathrm{E}-13$ $\exp (-5586 / \mathrm{T})) / 3$.

$e$ Treated as pinonic acid. Kwok and Atkinson (1995).

$f$ Treated as pinonaldehyde. Hjorth et al. (1996).

$g$ Treated as pinic acid. Kwok and Atkinson (1995).

${ }^{h}$ Treated as nopinone. Hjorth et al. (1996).

$i$ Treated as toluene.

$j$ Treated as xylene.

et al., 1996), the equilibrium between the gas and the aerosol phase of a condensable species $i$ that is produced from VOC oxidation and can partition between the two phases, is governed by:

$G_{i}=\frac{A_{i}}{K_{i} M_{o}}$,

where $G_{i}, A_{i}$ is the gas and the aerosol phase concentration of the species $i$ in $\mathrm{n} \mathrm{m}^{-3}$, respectively, $K_{i}$ is the partitioning coefficient of the species, in $\mathrm{m}^{3} \mu \mathrm{g}^{-1}$, and $M_{o}$ is the total particulate phase concentration in $\mu \mathrm{g} \mathrm{m}^{-3}$ :

$M_{o}=P P+\sum_{i} A_{i}$,

where $P P$ is the mass (in $\mu \mathrm{g} \mathrm{m}^{-3}$ ) of the primary particles that can serve as absorptive medium. The partitioning coefficient $K_{i}$ of the oxidation product $P_{i}$, is described by (Pankow, 1994a; Pankow, 1994b):

$K_{i}=\frac{760 R T f}{M W 10^{6} \zeta_{i} p_{L, i}^{0}}$, where $R$ is the gas constant, $f$ is the mass fraction of the total suspended particulate matter that acts as the absorbing phase, $M W$ is the mean molecular weight of the absorbing matter, $\zeta_{i}$ is the activity coefficient of compound $i$ in the particulate phase, $p_{L, i}^{0}$ is the vapour pressure of the compound $i$ in temperature $T$ and the factors 760 and $10^{6}$ apply for the conversion of units. Assuming that $f$ and $M W$ remain constant, the changes in $K_{i}$ with temperature can be calculated by applying the Clausius-Clapeyron equation (Atkins, 1990):

$\frac{d \ln p_{L, i}^{0}}{d T}=\frac{\Delta H_{i}}{R T^{2}}$,

where $\Delta H_{i}$ is the enthalpy of vaporization of the compound $i$. By combining (16) with (17) we get:

$K_{i}^{T}=K_{i}^{T_{S C}} \frac{1}{\zeta_{i}} \frac{T}{T_{S C}}\left[\frac{\Delta H_{i}}{R}\left(\frac{1}{T}-\frac{1}{T_{S C}}\right)\right]$,

where $K_{i}^{T}$ is the partitioning coefficient $K_{i}$ at temperature $T$, and $K_{i}^{T_{S C}}$ is the smog chamber measured value of $K_{i}$ at temperature $T_{S C}=298 \mathrm{~K}$ (Table 3). The value of $\Delta H$ is highly 


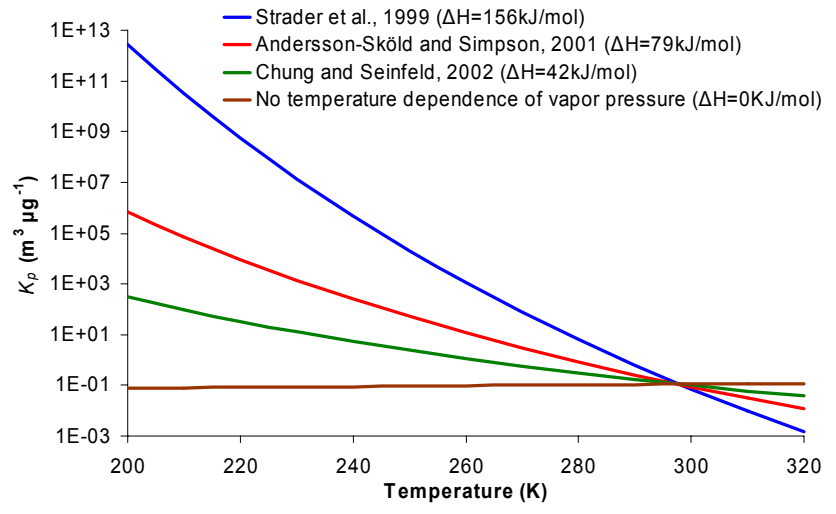

Fig. 1. Variation of $K_{p}$ with temperature, for the case $K_{p}=0.11$ at $298 \mathrm{~K}$.

uncertain and variable between species, and strongly affects the value of $K_{i}$ (Fig. 1).

The activity coefficient $\zeta_{i}$ of the individual components may change with time as a function of the chemical composition of the particulate phase. To take this into account, the multicomponent Wilson equation has to be used (Prausnitz, 1969; Bowman and Karamalegos, 2002):

$\ln \zeta_{i}=1-\ln \left(\sum_{j} x_{j} \Lambda_{i j}\right)-\sum_{k} \frac{x_{k} \Lambda_{i k}}{\sum_{j} x_{j} \Lambda_{j k}}$,

where $x_{i}$ is the mole fraction of the component $i, \Lambda_{i j}, \Lambda_{i k}$ and $\Lambda_{j k}$ are parameters representing the interactions between the compounds $i$ and $j, i$ and $k$ and $j$ and $k$, respectively, and all summations are over all species. For simplicity, component interactions are assumed symmetrical $\left(\Lambda_{i j}=\Lambda_{j i}\right)$. The $\Lambda$ values for the different species present in the carbonaceous aerosols (Table 2) have been selected on the base of the expected chemical similarity of the species and lie within the overall range of 0.2-1 given by Bowman and Karamalegos (2002) for highly dissimilar to identical in nature POA and semi-volatile compounds. In this manner, all secondary organic species are assumed to behave alike between them and quite similar to the hydrophilic primary organics. The hydrophobic primary organics behave less similar to the secondary organics. All organic aerosol species are not so similar to the hydrophobic particulate black carbon particles, while the hydrophilic black carbon fraction is assumed to be quite similar to the hydrophilic organic particles. In Table 2, $\Lambda$ values are also given for sulphuric and ammonia aerosol on which SOA could also partition. The $\Lambda$ values vary from 0.7 to 1 for dissimilar to similar with SOA compounds, expected to be representative for atmospheric conditions (Bowman and Karamalegos, 2002).

While the concentration of $A_{i}$ varies, $M_{o}$ also changes (15). If we assume that the total amount of semi-volatile products (both aerosol and gas-phase) repartition in each
Table 2. $\Lambda$ values used for the interactions $\left(\Lambda_{i j}\right)$ between species in carbonaceous aerosols. Note that only the interactions between SOA affect the aerosol production. The subscripts "ins" and "sol" declare the insoluble - hydrophobic and the soluble - hydrophilic fraction of the corresponding aerosol type, respectively. "Other" stands for non-carbonaceous aerosol

\begin{tabular}{ccccccc}
\hline & $\mathrm{SOA}$ & $\mathrm{OA}_{\text {ins }}$ & $\mathrm{OA}_{\text {sol }}$ & $\mathrm{BC}_{\text {ins }}$ & $\mathrm{BC}_{\text {sol }}$ & Other \\
\hline $\mathrm{SOA}$ & 1.0 & 0.8 & 0.9 & 0.7 & 0.8 & 0.7 \\
$\mathrm{OA}_{\text {ins }}$ & 0.8 & 1.0 & 0.8 & 0.8 & 0.7 & 0.8 \\
$\mathrm{OA}_{\text {sol }}$ & 0.9 & 0.8 & 1.0 & 0.7 & 0.8 & 0.7 \\
$\mathrm{BC}_{\text {ins }}$ & 0.7 & 0.8 & 0.7 & 1.0 & 0.8 & 0.7 \\
$\mathrm{BC}_{\text {sol }}$ & 0.8 & 0.7 & 0.8 & 0.8 & 1.0 & 0.8 \\
Other & 0.7 & 0.8 & 0.7 & 0.7 & 0.8 & 1.0 \\
\hline
\end{tabular}

timestep, then the aerosol concentration of each species is given by:

$A_{i}=\frac{\left(A_{i}^{0}+G_{i}^{0}+\Delta G_{i}^{p}\right) K_{i} M_{o}}{1+K_{i} M_{o}}$,

where $G_{i}^{0}$ and $A_{i}^{0}$ are the concentrations of the species $i$ in the gas and the aerosol phase, respectively in the previous timestep and $\Delta G_{i}^{p}$ is the change in the gas-phase concentration of the species $i$ due to chemical production (all products) and destruction (first generation products) in the current timestep. This approach assumes that all SOA has the potential to fully evaporate from the particle at each timestep. By solving the mass balance Eq. (15) using Eq. (20) we can calculate iteratively the value of $M_{o}$. In the present study the iterative solution for $M_{o}$ is calculated based on the bisectional method. The number of iterations depends on $M_{o}$ and on the relative error allowed that is prescribed to be $1 \%$ and not larger than $10 \mathrm{ng} \mathrm{m}^{-3}$. Then the aerosol concentrations can be derived from $M_{o}$ using Eq. (20) and subsequently the gasphase concentration of the species $i$ by applying Eq. (14).

However, if the semi-volatile organics undergo chemical or physical processes on particles (e.g. chemical reactions to form non-volatile compounds and/or inhibition of evaporation by other non-volatile components on the particle), the evaporation of SOA is being suppressed. It is expected that some reactions do occur on the particles but they do not necessarily transform the total amount of SOA to non-volatile. In that case by neglecting evaporation from the particles, an upper limit of the SOA production can be calculated and the equilibrium equation is applied only to the gas phase of the semi-volatile compounds.

When neglecting evaporation of the particles, Eq. (20) that gives the new aerosol concentration is modified to:

$A_{i}=A_{i}^{0}+\frac{\left(G_{i}^{0}+\Delta G_{i}^{p}\right) K_{i} M_{o}}{1+K_{i} M_{o}}$.

$M_{O}$ is calculated iteratively based on Eqs. (15) and (21). Then, the aerosol concentration $A_{i}$ is calculated by Eq. (21) 


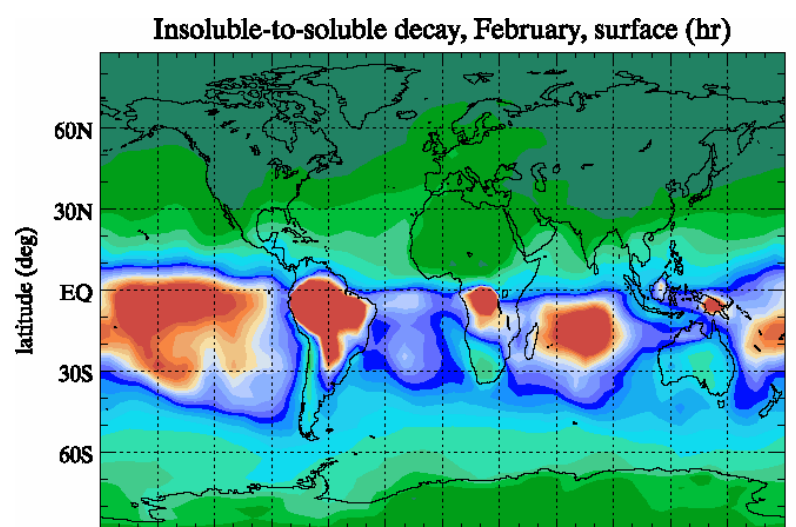

180W150W120W 90W 60W 30W OE 30E 60E 90E 120E 150E 180E longitude (deg)
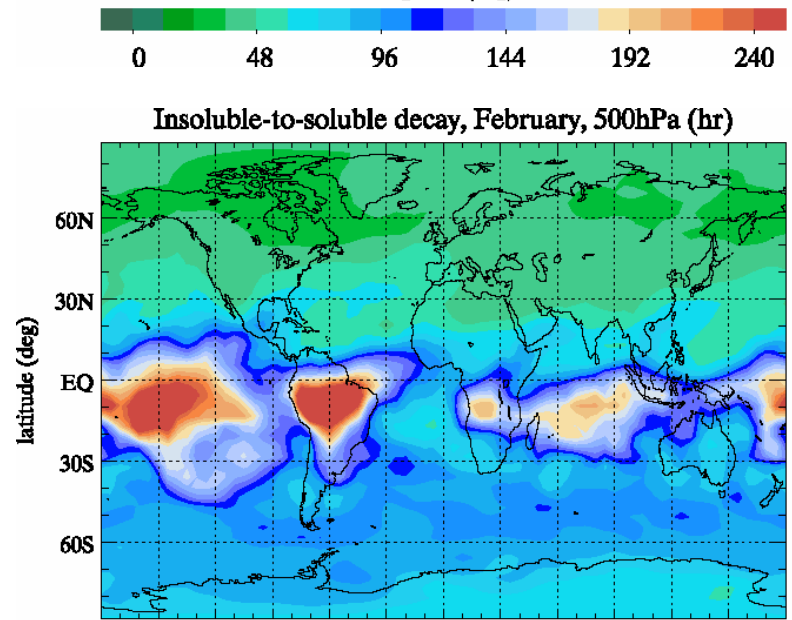

180W 150W 120W 90W 60W 30W OE 30E 60E 90E 120E 150E 180E longitude (deg)

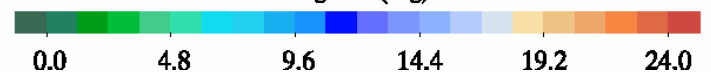

Insoluble-to-soluble decay, February, zonal mean (hr)

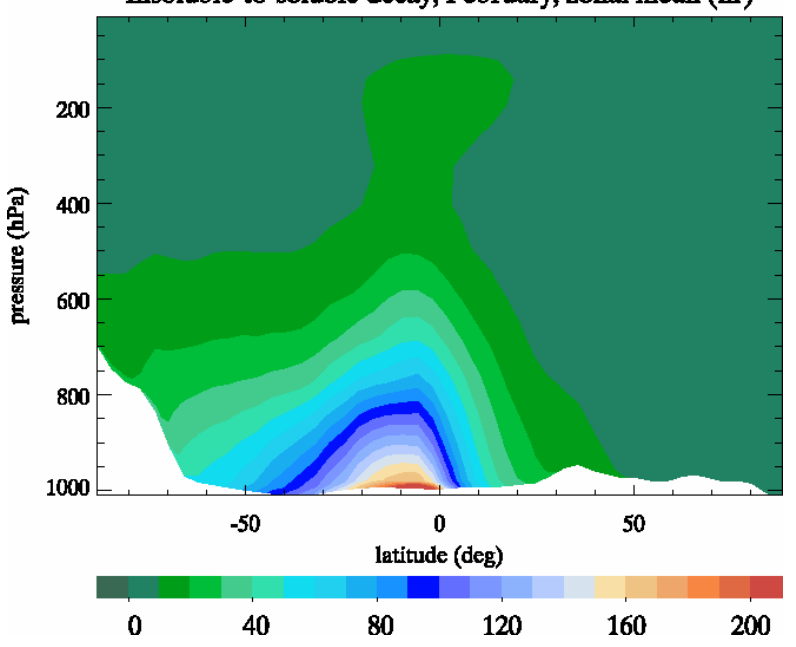

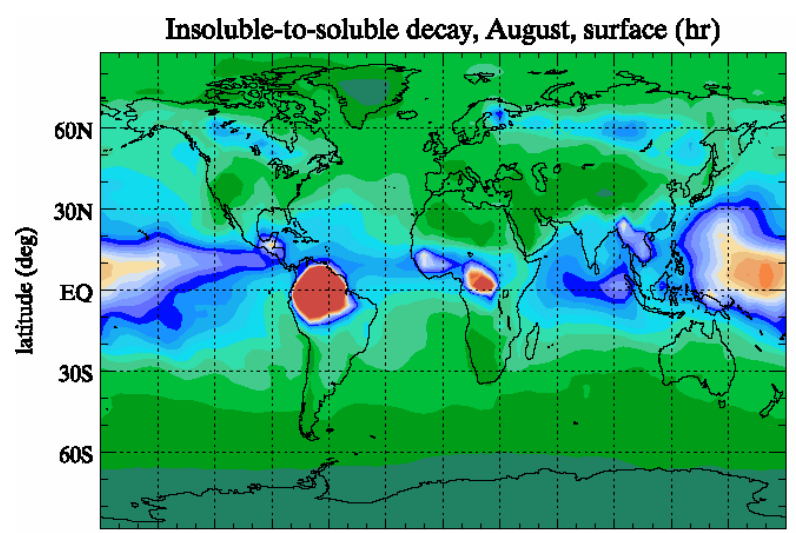

180W150W120W 90W 60W 30W OE 30E 60E 90E 120E 150E 180E longitude (deg)
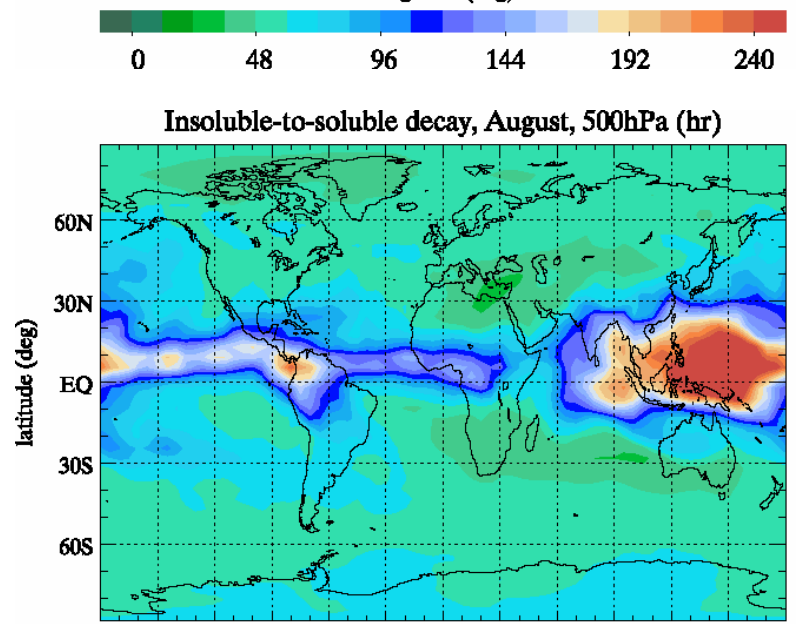

180W 150W120W 90W 60W 30W OE 30E 60E 90E 120E 150E 180E longitude (deg)

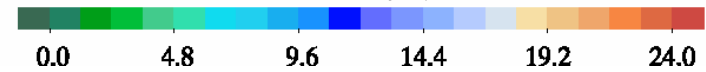

Insoluble-to-soluble decay, August, zonal mean (hr)

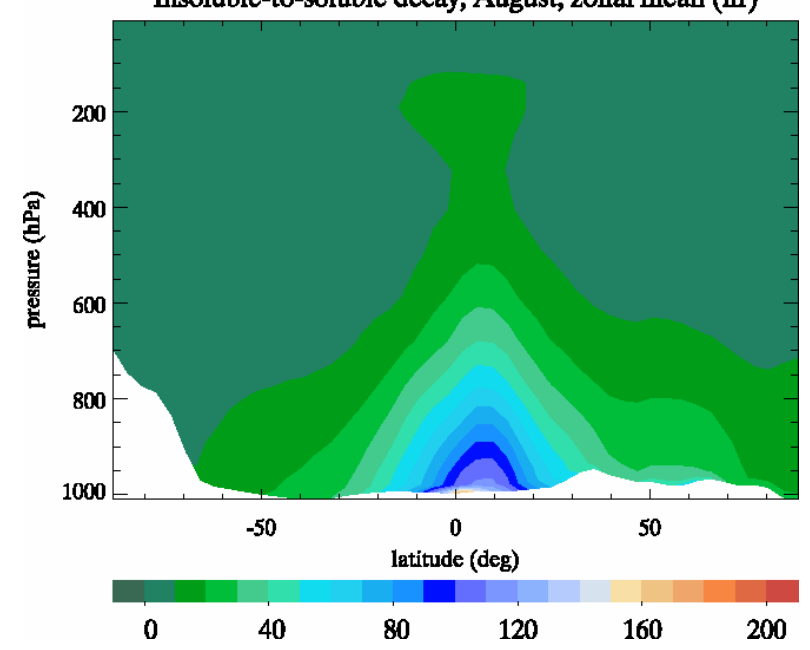

Fig. 2. Calculated lifetimes of hydrophobic primary carbonaceous aerosols for case $\mathrm{S} 1$ at surface (top panels), $500 \mathrm{hPa}$ (middle panels) and zonal mean (bottom panels) for February (left panels) and August (right panels). 
Table 3. Partitioning $(K)$ and stoicheiometric $(a)$ coefficients for biogenic and anthropogenic SOA formation

\begin{tabular}{ccccccc}
\hline & $\alpha$-pinene & & $\beta$-pinene & \\
& & toluene $^{b}$ & xylene $^{b}$ & $B_{b}$ & $B_{a}$ \\
\hline$a_{i 1}$ & 0.125 & 0.026 & 0.071 & 0.038 & 1.0 & 1.0 \\
$K_{i 1}$ & 0.088 & 0.195 & 0.053 & 0.042 & $c$ & $c$ \\
$a_{i 2}$ & 0.102 & 0.485 & 0.138 & 0.167 & 0 & 0 \\
$K_{i 2}$ & 0.0788 & 0.003 & 0.0019 & 0.0014 & - & - \\
\hline
\end{tabular}

${ }^{a}$ Oxidant $i$ is $\mathrm{O}_{3}$ (Griffin et al., 1999a).

${ }^{b}$ Oxidant $i$ is $\mathrm{OH}$ and $\mathrm{O}_{3}$ (Odum et al., 1997a, b).

${ }^{c}$ Maximum of the precursor species at given temperature.

and the gas-phase concentration $G_{i}$ by:

$G_{i}=G_{i}^{0}+\Delta G_{i}^{p}-\frac{\left(G_{i}^{0}+\Delta G_{i}^{p}\right) K_{i} M_{o}}{1+K_{i} M_{o}}=\frac{\left(G_{i}^{0}+\Delta G_{i}^{p}\right)}{1+K_{i} M_{o}}$.

As mentioned in Sect. 2.2, SOA formation from biogenic VOC oxidation initiated by $\mathrm{OH}$ is of minor importance relative to that by $\mathrm{O}_{3}$ and is neglected here. In addition, SOA formation by $\mathrm{NO}_{3}$ radical reactions with VOC, although occurring, is poorly studied and thus also neglected in the present work. These assumptions lead to an underestimation of the global SOA production and need future investigations.

\subsection{Ageing of primary hydrophobic aerosol}

To take into account the ageing of primary carbonaceous aerosol from hydrophobic to hydrophilic, we assume that this process occurs by oxidation of organic material that coats the particles by $\mathrm{O}_{3}$ as has been observed for soot particles in chamber experiments (Pöschl et al., 2001; Decesari et al., 2002). To parameterize this phenomenon we use the formulation experimentally determined by Pöschl et al. (2001) for soot particles coated by benzo $(\alpha)$ pyrene:

$r=\frac{r_{\infty} R_{\mathrm{O}_{3}}\left[\mathrm{O}_{3}\right]}{1+R_{\mathrm{O}_{3}}\left[\mathrm{O}_{3}\right]+R_{\mathrm{H}_{2} \mathrm{O}}\left[\mathrm{H}_{2} \mathrm{O}\right]}$,

where $R_{\infty}$ is the pseudo-first-order decay rate coefficient in the limit of high ozone concentrations and has been experimentally found to be equal to $0.015 \mathrm{~s}^{-1}, R_{\mathrm{O}_{3}}$ is the adsorption rate coefficient of $\mathrm{O}_{3}$ that serves as the oxidation medium and $R_{\mathrm{H}_{2} \mathrm{O}}$ is the adsorption rate coefficient of $\mathrm{H}_{2} \mathrm{O}$ that serves as an inhibitor by competitive adsorption. The adsorption rate coefficients of $\mathrm{O}_{3}$ and $\mathrm{H}_{2} \mathrm{O}$, are computed following the equation by Pöschl et al. (2001):

$R_{i}=\frac{S_{0, i} \omega_{i}}{4[S S]_{s}} \tau_{i}$,

where $S_{0, i}$ is the sticking coefficient of $\mathrm{O}_{3}$ and $\mathrm{H}_{2} \mathrm{O}$ $\left(3.3 \cdot 10^{-3}\right.$ and $0.4 \cdot 10^{-3}$, respectively), $\omega_{i}$ is the mean thermal velocity, $[S S]_{s}$ is the surface concentration of adsorption sites for the studied soot particles and measured to be $5.7 \cdot 10^{14}$ sites $\mathrm{cm}^{-2}$ and $\tau_{i}$ is the mean residence time of $\mathrm{O}_{3}$ and $\mathrm{H}_{2} \mathrm{O}$ on particle surface sites, measured to be $5 \mathrm{~s}$ and $3 \cdot 10^{-3} \mathrm{~s}$, respectively.

We assume that the conversion of hydrophobic to hydrophilic aerosol occurs when a monolayer of hydrophilic carbonaceous material is formed. To parameterize this phenomenon we adopted a mean aerosol size of $0.25 \mu \mathrm{m}$ and a monolayer thickness of $2.5 \mathrm{~nm}$ from the particle surface.

POA ageing is treated similarly to the ageing process of hydrophobic BC, since the POA contains also aromatic groups (Fuzzi et al., 2001) like those coating the soot particles. The validity of this hypothesis for the entire primary carbonaceous aerosol though is questionable since benzo $(\alpha)$ pyrene is probably not the most adequate compound to represent the primary carbonaceous aerosol and thus requires to be experimentally checked.

The thus calculated lifetimes of hydrophobic primary carbonaceous aerosols are shown in Fig. 2. Note that the calculated values are of the same order of magnitude with the values reported by Cooke et al. (1999) for the whole troposphere, and with high spatial differences. In the tropics, where relative humidity is much higher than the midlatitudes the parameterization based on $\mathrm{O}_{3}$ oxidation gives higher lifetime for the hydrophobic aerosols, since water inhibits the hydrophobic-to-hydrophilic conversion. Also note that longest lifetimes of hydrophobic aerosol are calculated for areas with low concentrations of ozone, which acts as the oxidation medium for this conversion. In the northern hemisphere the lifetime increases during summer due to increased water vapour concentrations. The simultaneous increase in ozone is not able to reduce the hydrophobic aerosol lifetime since the inverse effect of humidity is stronger. The same applies to the summer of the south hemisphere.

\subsection{Wet and dry deposition}

The wet deposition of the gas-phase aerosol precursors depends on their solubility in cloud droplets according to their Henry's law coefficients $(H)$. The parent VOCs are poorly soluble and have low Henry's law constants, making their wet deposition negligible. On the contrary, the first generation products are better soluble, since they consist of multi-functional compounds including carbonylic and 
Table 4. Outline of simulations performed in this study

\begin{tabular}{|c|c|}
\hline Simulation & Description \\
\hline S1 & $\begin{array}{l}\text { Partitioning on carbonaceous aerosols, with evaporation, } \Delta H=42 \mathrm{KJ} \mathrm{mol}^{-1} \text {, } \\
\text { without oxidation of the first generation semi-volatile products, the hydrophobic } \\
\text { to hydrophilic conversion depends on } \mathrm{O}_{3} \text { and } \mathrm{H}_{2} \mathrm{O}-\text { Sect. } 2.4\end{array}$ \\
\hline S1.1 & As $\mathrm{S} 1, \Delta H=79 \mathrm{KJ} \mathrm{mol}^{-1}-$ Eq. (18) \\
\hline $\mathrm{S} 1.2$ & As $\mathrm{S} 1, \Delta H=0 \mathrm{KJ} \mathrm{mol}^{-1}-$ Eq. (18) \\
\hline S1.3 & As S1, with oxidation of the primary condensable products - Sect. 2.2 \\
\hline S1.4 & As S1, without dependence on the activity coefficient - Eq. (19) \\
\hline S1.5 & As S1, with strong dependence on the activity coefficient - Eq. (19) \\
\hline S1.6 & As S1, with double primary carbonaceous aerosol emissions - Sect. 2.1 \\
\hline S1.7 & As S1, with constant conversion rate of hydrophobic to hydrophilic aerosols - Sect. 2.4 \\
\hline S1.8 & As S1, without conversion of hydrophobic to hydrophilic aerosols - Sect. 2.4 \\
\hline $\mathrm{S} 2$ & As S1, irreversible sticking of SOA on pre-existing aerosol \\
\hline S3 & As S1, including the partitioning on sulphuric and ammonium aerosol \\
\hline S4 & As S3, irreversible sticking of SOA on pre-existing aerosol \\
\hline
\end{tabular}

carboxylic groups, while the second generation products are expected to have even more functional groups. From the compilation of Henry's law coefficients by Sander (1999), $H$ is $\approx 10^{3}-10^{4}$ for monocarboxylic acids and $H$ is $\approx 10^{6}-$ $10^{8} \mathrm{M} \mathrm{atm}^{-1}$ for dicarboxylic acids. Hence, a Henry coefficient of $10^{3}$ for most first generation products and $10^{6}$ for the secondary products has been used, except $\alpha$-pin- $P_{1}, \beta$-pin$P_{1}$ and xyl- $P_{1}$ that are assumed to behave as pinonic acid (keto-monocarboxylic acid), pinic acid (dicarboxylic acid) and toluic acid, respectively. For these acids the Henry values have been assumed to be $10^{4}, 10^{6}$ and $10^{4}$, respectively. The temperature dependence of Henry coefficients is described by (Sander, 1999):

$\frac{d \ln H}{d T}=\frac{\Delta H_{i}}{R T^{2}}$,

where $\Delta H_{i}$ is the heat of dissolution and equals to $-12 \mathrm{~K}$ (Sander, 1999) for all compounds. For the dry deposition of the gaseous species, the Ganzeveld and Lelieveld (1995) scheme has been used, which is based on the formulation developed by Wesely (1989). For the aerosol phase, wet and dry deposition is parameterized as suggested by Parungo et al. (1994) and already applied to sulphate particles in the model (Jeuken et al., 2001).

\section{The simulations}

A number of global simulations have been performed to investigate uncertainties associated with the model results and determine a possible range of annual global SOA production. Several factors of uncertainty in the model calculations have been studied, like the primary carbonaceous emissions, the amount and nature of pre-existing absorbing aerosol, the effect of evaporation of semi-volatile products from the par- ticulate phase, the temperature dependence of the partitioning coefficient $K_{i}$ of a compound due to the enthalpy of vaporization, the solubility and the activity coefficient of the condensable species, the chemical fate of the first generation semi-volatile oxidation products of VOC, precursors of SOA and the ageing of particles with regard to their hydrophilic properties. For this purpose, simulation $\mathrm{S} 1$ has been modified appropriately and has been used as a reference case for simulations S1.1 to S1.8 and S2 to S4. These simulations are summarized in Table 4.

\subsection{Impact of the absorbing matter and evaporation - irre- versible sticking - cases S2, S3, S4, S1.6}

Simulations S1 and S3 (as well as S2 and S4) differ on the amount and nature of the absorbing aerosol phase. S1 considers only the condensation on carbonaceous aerosols, both organic and $\mathrm{BC}$, while $\mathrm{S} 3$ assumes that condensation also occurs on sulphuric (sulphate and methanesulphonate) and ammonium aerosols, for instance by absorption. Note that $\mathrm{BC}$ consists both from graphitic carbon and organic material at percentages not precisely quantified. Therefore, in our study we include black carbon as an absorptive medium for SOA with decreased ability compared to the preexisting SOA. This is parameterized using $\Lambda$ values of 0.7 (for hydrophobic $\mathrm{BC}_{\mathrm{ins}}$ ) to 0.8 (for hydrophilic $\mathrm{BC}_{\mathrm{sol}}$ ) that is smaller than that of 1.0 adopted for SOA (Eq. 19; Table 2). For ammonium and sulphate aerosol types the $\Lambda$ value of 0.7 is used. Simulations S1 and S2 (as well S3 and S4) differ on the consideration of evaporation of pre-existing semi-volatile products. S1 and S3 consider that the semi-volatile products can evaporate from the particles whereas in S2 and S4 irreversible sticking is assumed to occur on the particles.

The sensitivity of the model results to the emissions of primary carbonaceous aerosols has been tested by doubling 
Table 5. Global annual SOA production performed using the results of chamber experiments, versus the results of the present 3-D global modelling study

\begin{tabular}{|c|c|c|c|c|c|c|}
\hline $\begin{array}{l}\text { Production } \\
\left(\operatorname{Tg~}^{-1}\right)\end{array}$ & Case & $\begin{array}{l}\text { VOC precursors } \\
\text { (number) }\end{array}$ & $\begin{array}{l}\text { Pre-existing } \\
\text { particles }^{a}\end{array}$ & Evaporation & $\begin{array}{l}\text { Transport of } \\
\text { intermediates }\end{array}$ & Reference \\
\hline $13-24$ & Present day & Biogenic (30) & No & No & No & Griffin et al. (1999b) \\
\hline $61-79$ & Present day & Biogenic (2) & $\mathrm{C}$ & No & No & Kanakidou et al. (2000) \\
\hline $16.5-28$ & Pre-industrial & Biogenic (2) & $\mathrm{C}$ & No & No & Kanakidou et al. (2000) \\
\hline 11.2 & Present day & Biogenic (5) & $\mathrm{C}$ & Yes & Yes & Chung and Seinfeld (2002) \\
\hline 63 & Present day & Biogenic (1) & $\mathrm{C}$ & Yes & Yes & Derwent et al. (2003) \\
\hline \multirow[t]{2}{*}{$7.2(0.3)^{b}$} & Present day & Biogenic (2) & & & & \\
\hline & & $\&$ anthropogenic (2) & $\mathrm{C}$ & Yes & Yes & This work - S1 \\
\hline \multirow[t]{2}{*}{$44.0(2.0)^{b}$} & Present day & Biogenic (2) & & & & \\
\hline & & \& anthropogenic (2) & $\mathrm{C}$ & No & Yes & This work $-\mathrm{S} 2$ \\
\hline \multirow[t]{2}{*}{$13.3(0.7)^{b}$} & Present day & Biogenic (2) & & & & \\
\hline & & \& anthropogenic (2) & CSN & Yes & Yes & This work - S3 \\
\hline \multirow[t]{2}{*}{$44.5(2.6)^{b}$} & Present day & Biogenic (2) & & & & \\
\hline & & $\&$ anthropogenic (2) & $\mathrm{CSN}$ & No & Yes & This work - S4 \\
\hline
\end{tabular}

${ }^{a} \mathrm{C}$ : Carbonaceous aerosols, CSN: Carbonaceous, sulphate, methanesulphonate and ammonium aerosols ${ }^{b}$ Read as: Biogenic VOC contribution to SOA (Anthropogenic VOC contribution to SOA)

the emitted amounts in case S1.6. because as mentioned in Sect. 2.1 the inventory of carbonaceous aerosols is highly uncertain.

\subsection{Temperature effect - cases S1.1 and S1.2}

To investigate the effect of temperature on the partitioning of semi-volatile organics between the gas and aerosol phase, different enthalpies of evaporation $\Delta H$ have been used in Eq. (18) to calculate the partitioning coefficient as a function of temperature (Strader et al., 1999; Andersson-Sköld and Simpson, 2001; Chung and Seinfeld, 2002). Very large differences up to 10 orders of magnitude in low temperatures are calculated and depicted in Fig. 1. Such differences result in critical discrepancies between the models and need to be reduced by adequate experimental studies to provide a more accurate estimate of the SOA production, especially in high latitudes during winter and at high altitudes in the mid and upper troposphere. To evaluate the errors in the model calculations due to the uncertainty in the enthalpy of vaporization, an additional calculation of the SOA production is made by adopting the $\Delta H$ value of $79 \mathrm{KJ} \mathrm{mol}^{-1}$ (Andersson-Sköld and Simpson, 2001; case S1.1) that is close to recent data by Pun et al. (2003) whereas case S1.2 considers that the vapour pressure does not vary with temperature.

3.3 Hydrophobic to hydrophilic conversion - cases S1.7 and S1.8

The spatial and temporal variability of the hydrophobic to hydrophilic aerosol conversion rate is also a source of uncertainty and has been parameterised in case $\mathrm{S} 1$ as described in
Sect. 2.4) assuming that the organics in the particulate phase can be represented by benzo $(\alpha)$ pyrene. This work has to be considered as a first effort to apply a spatially and temporally variable conversion rate of hydrophobic to hydrophilic aerosol. This has been compared to the approach by Cooke et al. (1999), i.e. by applying a globally constant hydrophobic to hydrophilic conversion rate corresponding to 1.15 days turnover time (case S1.7). To investigate the importance of this conversion for the SOA burden, an additional simulation has been performed by neglecting the transition of hydrophobic to hydrophilic aerosol (case S1.8).

\subsection{Secondary oxidation products - case S1.3}

The gas phase oxidation of the SOA precursor species mentioned in Sect. 2.2 produces the first generation semi-volatile products that are able to partition between the gas and aerosol phase. These can, in turn, further oxidize in the gas-phase and give secondary semi-volatile products that can also partition. This hypothesis is taken into account in case S1.3 and is not contradicted by the smog chamber experiments. Simple box model calculations considering the $\alpha$ - and $\beta$-pinene oxidation as described in Sect. 2.2 have been performed using conditions close to Griffin et al. (1999a) experiments. They show that the calculated difference in the aerosol yield between $\mathrm{S} 1$ and $\mathrm{S} 1.3$ exceeds $2 \%$ after more than $10 \mathrm{~h}$. To our knowledge, most chamber experiments do not last long enough to detect these expected differences in the aerosol yield that are also within the uncertainty of the experimental data. However, this procedure might be important globally and in longer timescales and has been therefore investigated here on the basis of the simulation S1.3. 
Table 6. Global annual SOA production, changes in SOA chemical production with regard to the reference case $\mathrm{S} 1$ in percent and global annual mean SOA burden (from surface up to $10 \mathrm{hPa}$ ) calculated in all studied cases of this work

\begin{tabular}{cccccc}
\hline & \multicolumn{2}{c}{ Chem. prod. } & \% change & \multicolumn{2}{c}{ Burgen } \\
TG y & from S1 & \multicolumn{2}{c}{ Gg } \\
Case & SOAb & SOAa & & SOAb & SOAa \\
\hline S1 & 7.2 & 0.27 & 0 & 47.5 & 2.2 \\
S1.1 & 18.3 & 1.05 & +159 & 115.6 & 7.8 \\
S1.2 & 2.5 & 0.05 & -66 & 13.7 & 0.5 \\
S1.3 & 8.8 & 0.24 & +21 & 54.6 & 2.1 \\
S1.4 & 7.7 & 0.29 & +7 & 51.6 & 2.5 \\
S1.5 & 6.6 & 0.24 & -8 & 41.8 & 1.9 \\
S1.6 & 8.7 & 0.36 & +21 & 59.0 & 2.9 \\
S1.7 & 6.7 & 0.28 & -7 & 44.9 & 2.2 \\
S1.8 & 13.4 & 0.71 & +89 & 85.8 & 4.8 \\
S2 & 44.0 & 2.02 & +516 & 369.8 & 24.6 \\
S3 & 13.3 & 0.70 & +87 & 105.1 & 6.3 \\
S4 & 44.5 & 2.62 & +531 & 356.9 & 27.3 \\
\hline
\end{tabular}

\subsection{Activity coefficient - cases S1.4 and S1.5}

The partitioning coefficient of the semi-volatile products used in this study has been measured in chamber studies with almost pure SOA. In the real atmosphere though, the mixed aerosols have non-uniform physicochemical properties. These differences have been taken into account in Eq. (16) by the use of the activity coefficient that is calculated in Eq. (19). The $\Lambda$ values used in this equation lie within the expected range representative for typical atmospheric conditions (Bowman and Karamalegos, 2002). To evaluate the model sensitivity to the variation of the activity coefficient of SOA with the aerosol chemical composition simulations have been performed both neglecting its variation $\zeta_{i}=1$ in Eq. (16); case S1.4) and assuming a stronger influence of the activity coefficient (all $\Lambda$ values equal to 0.7 , reflecting semi-volatile organic compounds less similar to the aerosol components; case S1.5).

\section{Budget calculations}

The calculations of the global annual SOA production performed using the results of chamber experiments for the four different cases (S1 to S4) are summarized and compared with earlier global modelling studies in Table 5. Our model results are within the range of earlier estimates by Griffin et al. (1999b), Kanakidou et al. (2000), Chung and Seinfeld (2002) and Derwent et al. (2003). In order to understand the differences between the different model results, including the present work, we need to compare the different assumptions of the various model studies. All models follow rather different approaches; they assume different substrates for the con- densation of SOA as well as the surrogate VOC compounds considered to form SOA precursors and have different treatment of the evaporation. They also differ in the consideration or not of primary carbonaceous aerosol and in the amount of it that is being emitted into the atmosphere. To these conceptual particularities of the models, more generally applied technical differences are added like the spatial and temporal resolutions of the models, the parameterizations and input data used to represent transport and wet deposition processes. Such differences have been identified in the past to contribute to large discrepancies in the concentration of radionuclides and sulphate aerosols that have more simple production and decay terms than SOA (Jacob et al., 1997; Barrie et al., 2001). Therefore, only the use of the same global model for different simulations as performed in the present study can clarify differences.

When comparing the models that do not include evaporation of the particles, Kanakidou et al. (2000) calculate a much higher SOA production compared to Griffin et al. (1999b), since the latter assumes the condensation of semi-volatile compounds only on pre-existing SOA and not on primary carbonaceous particles. This assumption leads to much lower pre-existing particle concentrations which can serve as absorptive matter for newly formed condensable products. The results of Kanakidou et al. (2000) can also be compared with S2 that considers condensation of SOA only on carbonaceous aerosols. The present study (S2) has been performed with a higher resolution model and with updated, slightly lower (about $40 \mathrm{Tg}^{-1}$ versus $73 \mathrm{Tg}^{-1}$ ), primary carbonaceous particle emissions. Thus $\mathrm{S} 2$ results in about $30 \%$ lower SOA formation than that earlier estimate. Chung and Seinfeld (2002) also use higher POA emissions by a factor of 2 than $\mathrm{S} 1\left(81 \mathrm{Tg}^{-1}\right)$. When doubling the primary carbonaceous emissions in our model (S1.6 to be compared with S1), the global annual chemical production of SOA and the corresponding burden in the model domain are enhanced only by $20 \%$ and $24 \%$, respectively. Therefore about $25 \%$ of uncertainty associated with the primary carbonaceous aerosol emissions should be expected on the SOA budget. Larger increases (about 87\%) are calculated when considering that condensation of SOA occurs also on aerosols other than carbonaceous (S3 compared with S1). Comparison of S2 with S4, considering that condensation occurs also on sulphuric and ammonium aerosols in addition to carbonaceous particles and irreversible sticking of semi-volatile organics, results in little additional SOA from biogenic VOC but relatively much higher increase of SOA coming from anthropogenic VOC, since this additional aerosol surface is present mainly over anthropogenically affected areas.

The model simulations that consider SOA evaporation give relatively lower global SOA formation estimate than simulations considering irreversible sticking of the semivolatile organics on the particles. The budget seems to conditionally depend on the total aerosol in the model and maximises in cases S2 and S4 reaching approximately the same 


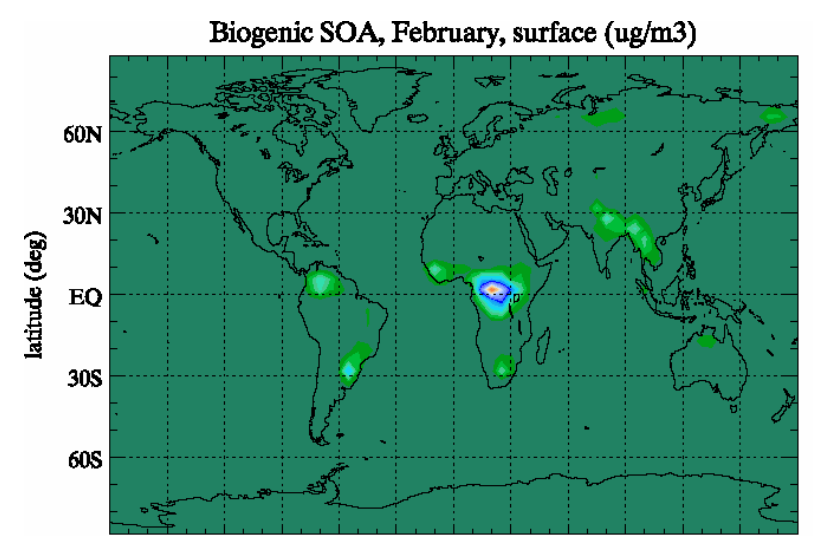

180W150W120W 90W 60W 30W 0E $30 \mathrm{E} \quad 60 \mathrm{E} \quad 90 \mathrm{E} \quad 120 \mathrm{E} 150 \mathrm{E} 180 \mathrm{E}$ longitude (deg)
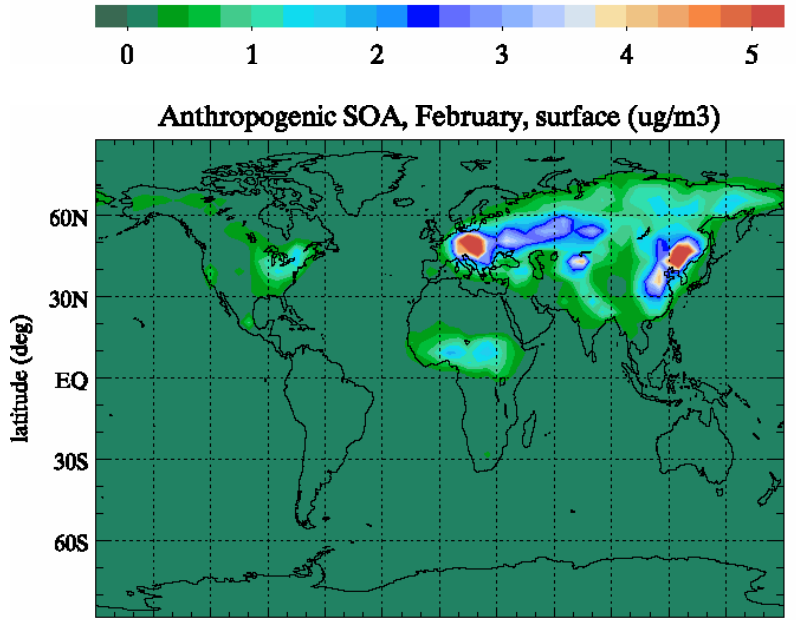

180W150W120W 90W 60W 30W OE $30 \mathrm{E} \quad 60 \mathrm{E}$ 90E 120E $150 \mathrm{E} 180 \mathrm{E}$ longitude (deg)

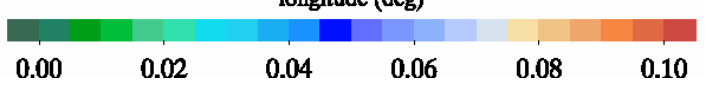

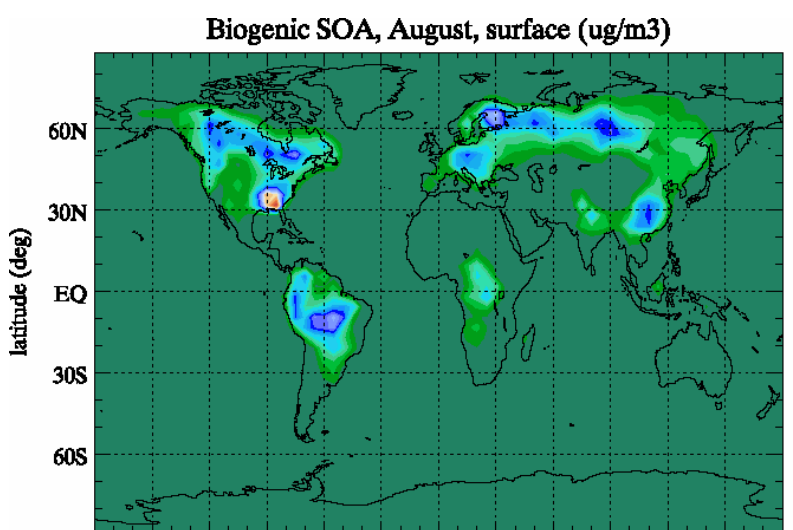

180W150W120W 90W 60W 30W 0E $30 \mathrm{E} \quad 60 \mathrm{E} \quad 90 \mathrm{E} \quad 120 \mathrm{E} 150 \mathrm{E} 180 \mathrm{E}$ longitude (deg)

\begin{tabular}{llllll}
\hline & 1 & 2 & 3 & 4 & 5
\end{tabular}

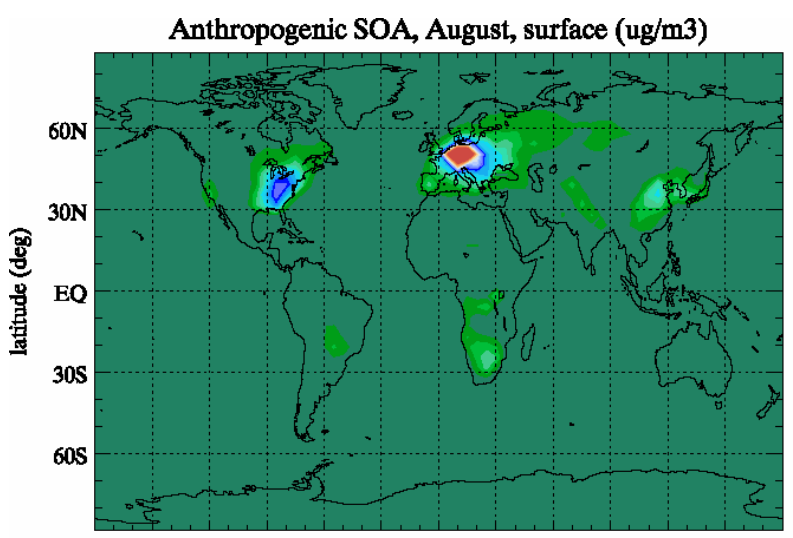

180W150W120W 90W 60W 30W OE $30 \mathrm{E} \quad 60 \mathrm{E}$ 90E 120E $150 \mathrm{E} 180 \mathrm{E}$ longitude (deg)

\begin{tabular}{llllll}
\hline 0.00 & 0.02 & 0.04 & 0.06 & 0.08 & 0.10
\end{tabular}

Fig. 3. Calculated surface SOA concentrations for case $\mathrm{S} 1$, both biogenic (SOAb in $\mu \mathrm{g} \mathrm{m}^{-3}$, top panels) and anthropogenic (SOAa in $\mu \mathrm{g} \mathrm{m}^{-3}$, bottom panels) components, for February (left panels) and August (right panels).

level of about $45 \mathrm{Tg}^{-1}$ that appears in these two cases independent of the pre-existing aerosol. This is in agreement with smog chamber experiments showing that at high aerosol loading the aerosol yield depends on the stoichiometric coefficient $\left(a_{i}\right)$ of the semi-volatile products (Seinfeld and Pankow, 2003). In these simulations the SOA chemical formation is expected to be mainly determined by the adopted lumped chemistry for the formation of semi-volatile SOA precursors. The higher SOA production calculated by Chung and Seinfeld (2002) compared with case S1 is possibly due to the consideration by these authors of SOA formation from all 3 oxidant reactions of VOC, also considered by Derwent et al. (2003). This difference can also reflect the disparity in the number of surrogate species of each model.

It can also partly reflect the differences in the partitioning coefficients of the semi-volatile precursors of SOA and the corresponding enthalpies of vaporisation $(\Delta H)$. According to our simulations S1.1 and S1.2 this factor can provide large positive or negative deviations when compared to S1 (up to $160 \%$ for the studied cases). The enthalpy of vaporisation seems to be a major source of uncertainty in SOA budget that requires improvements in our knowledge. Since the hydrophilic aerosols are faster removed from the troposphere by dry and wet deposition than the hydrophobic ones, the burden of carbonaceous aerosols in case S1.8 is higher than in case S1. This appears to be a critical factor of uncertainty, since the chemical production of SOA is almost doubled in case S1.8 and the corresponding burden increases by about $80 \%$. In addition, the variable conversion rate approach (S1) compared to the constant turnover time (S1.7) is overestimating the SOA production above tropical areas with strong primary carbonaceous aerosol sources by about $10 \%$, whereas it makes only a $6 \%$ overestimate to the chemical production of biogenic SOA (Table 6). 


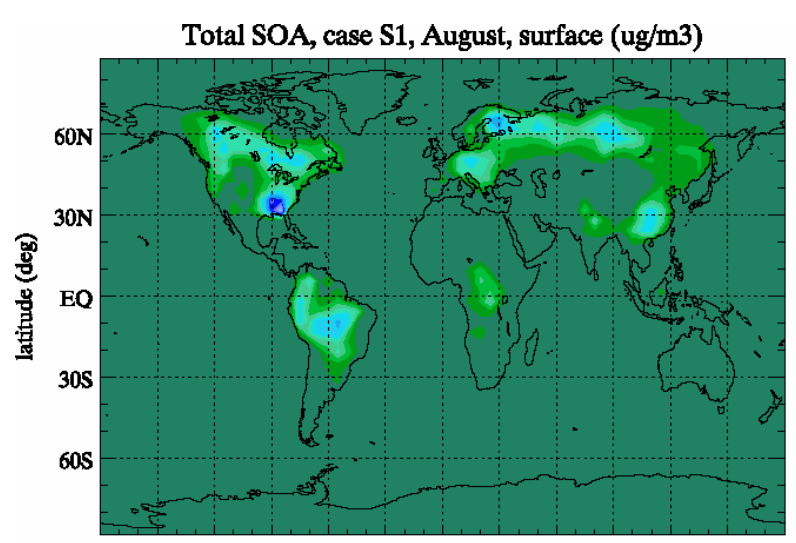

180W150W120W 90W 60W 30W OE 30E 60E 90E 120E 150E 180E longitude (deg)

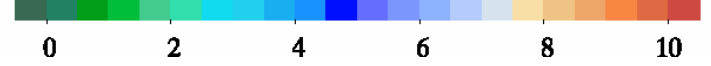

Total SOA, case S3, August, surface (ug/m3)

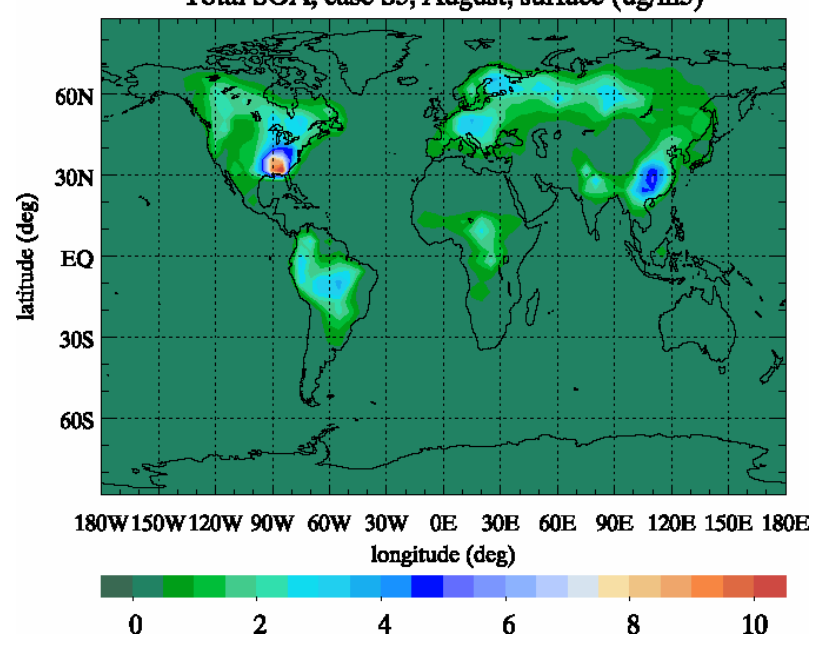

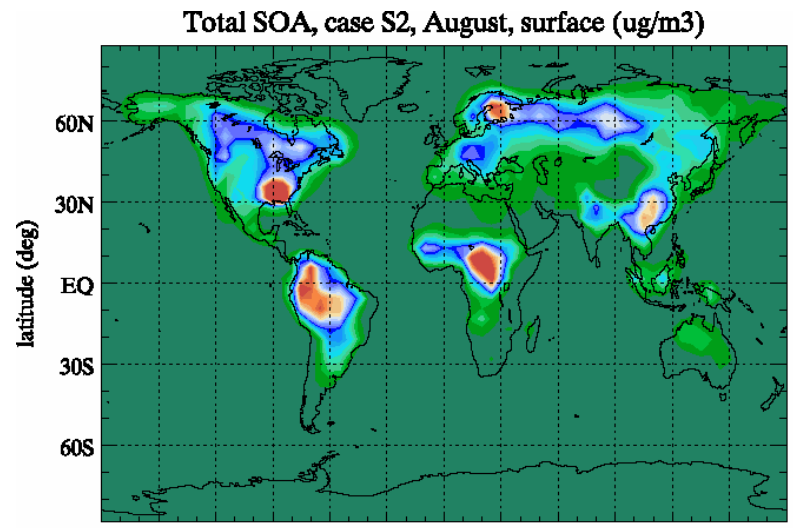

180W 150W 120W 90W 60W 30W OE 30E 60E 90E 120E 150E 180E longitude (deg)

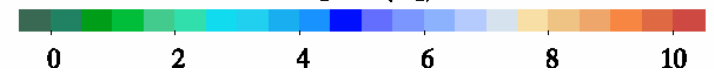

Total SOA, case S4, August, surface (ug/m3)

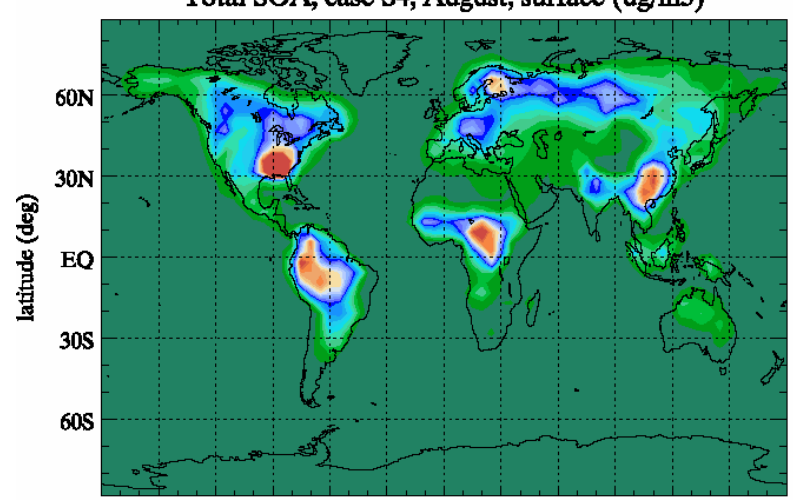

180W150W120W 90W 60W 30W OE 30E 60E 90E 120E 150E 180E longitude (deg)

$\begin{array}{llllll}0 & 2 & 4 & 6 & 8 & 10\end{array}$

Fig. 4. Comparison of the total SOA concentrations in $\mu \mathrm{g} \mathrm{m}^{-3}$ (sum of biogenic and anthropogenic) of cases S1 (top-left panel), S2 (top-right panel), S3 (bottom-left panel) and S4 (bottom-right panel) for August.

The model is not very sensitive to the variation of the activity coefficient of SOA with the aerosol composition since simulations S1.4 and S1.5 add an uncertainty of about $\pm 10 \%$ to the estimated SOA global budget when considering $\Lambda$ values within the expected range representative for atmospheric conditions.

\section{Calculated SOA distributions}

Figure 3 shows the calculated SOA concentrations for the lowest model level (surface), corresponding to both SOA formed during biogenic VOC oxidation (SOAb) and SOA formed during anthropogenic VOC oxidation (SOAa) components, for February and August for the case S1 that is used as a reference case in the present study. The calculated concentration of SOA produced from biogenic VOC oxidation exceeds that from anthropogenic one by an order of magnitude and particularly the maximum SOAb is by about 30 times (30 in February, 36 in August) higher than the maximum SOAa concentration.

The annual production of SOAb is calculated to be higher by more than a factor of 25 than that of SOAa. SOAa contributes to the total SOA concentration by $30 \%$ to $65 \%$ above and downwind of industrialized areas in the northern hemisphere where its contribution maximizes during winter and becomes less than $15 \%$ during summer when biogenic VOC emissions are high. These numbers show that although the global annual SOA production is by far dominated by the biogenic VOC, in industrialized areas during the winter when the emissions of biogenic VOC are very low, the anthropogenic hydrocarbons can contribute significantly to the total secondary organic aerosol. 

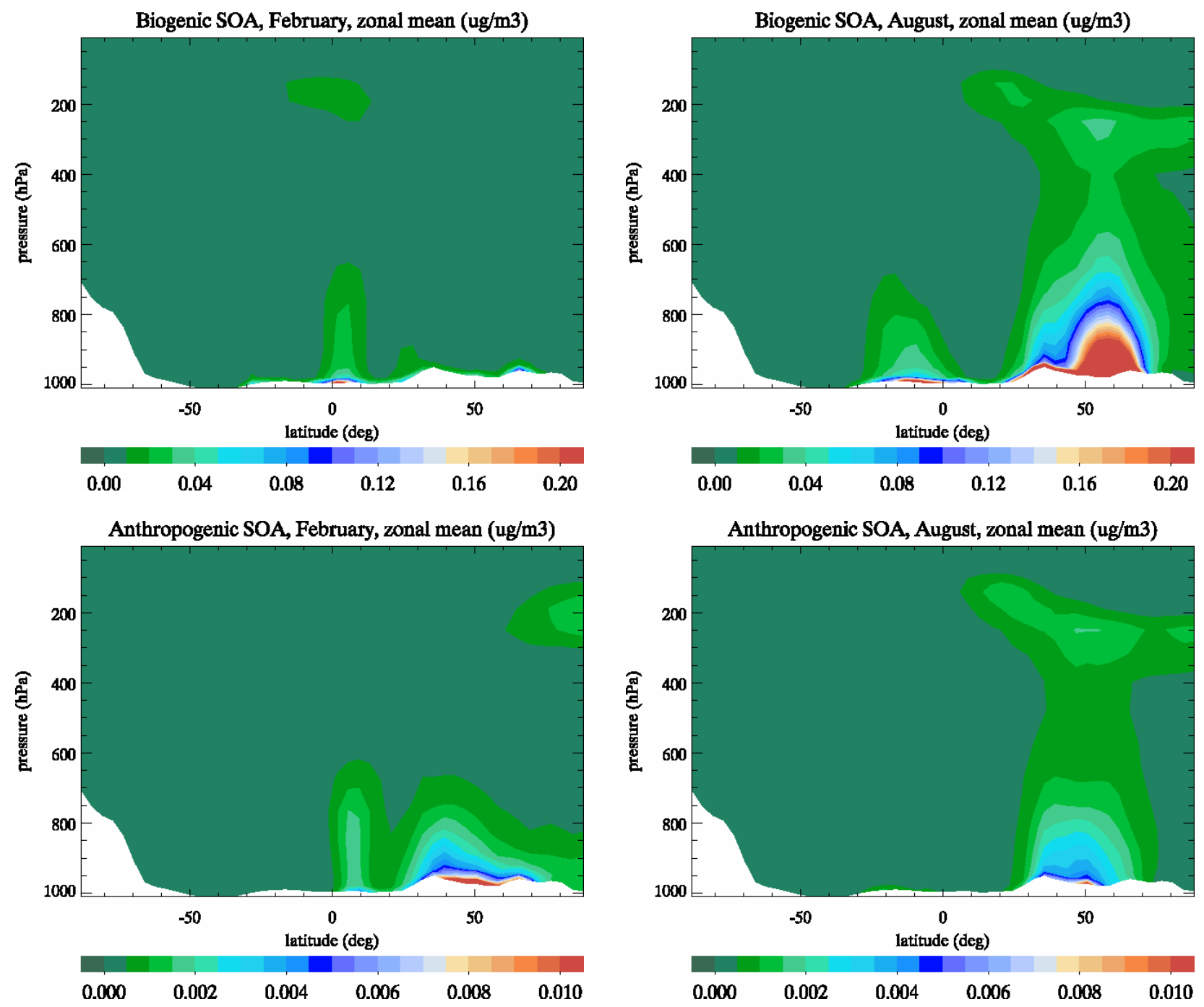

Fig. 5. Calculated zonal mean SOA concentrations for case $\mathrm{S} 1$, both biogenic (SOAb (in $\mu \mathrm{g} \mathrm{m}^{-3}$ ), top panels) and anthropogenic (SOAa (in $\mu \mathrm{g}^{-3}$ ), bottom panels) components, for February (left panels) and August (right panels).

Similar patterns are calculated for SOA distributions when considering condensation also on sulphuric and ammonium aerosols (cases S3 and S4), and when assuming irreversible sticking of semi-volatile products onto the aerosol phase (cases S2 and S4). The SOA surface distribution of cases S1, S2, S3 and S4 are depicted in Fig. 4 for comparison. Although the patterns are similar, the absolute concentrations increase from S1 to S3 to S2 to S4. In particular, the maximum calculated total SOA concentrations for August increase by factors of 1.7, 3.0 and 3.4 for S3, S2 and S4, respectively. In addition, enhancements of SOA concentrations over continental tropics are calculated when irreversible sticking is assumed (cases S2 and S4) due to both the high air temperature favouring evaporation and the vicinity of intensive SOA sources.
The zonal mean concentrations for February and August, again for the case S1, for SOAb and SOAa are shown in Fig. 5. Both for SOAb and SOAa, the upper troposphere local maximum is due to condensation of the gas-phase compounds transported at these altitudes, where temperatures are very low and thus the partitioning coefficient is high.

These vertical distributions of SOA are affected from the temperature changes when varying the enthalpy of vaporization of the condensable SOA precursors (S1.1. and S1.2) or when considering that the primary condensable products can further oxidize to lower volatility secondary ones (S1.3).

The effect of temperature on the partitioning coefficients of the semi-volatile compounds is reflected on the differences in the calculated total SOA concentrations (sum of biogenic and anthropogenic, case S1.1) when adopting the high value for the enthalpy of evaporation and the reference case S1 are 
Total SOA difference, case S1.1, August, surface (ug/m3)

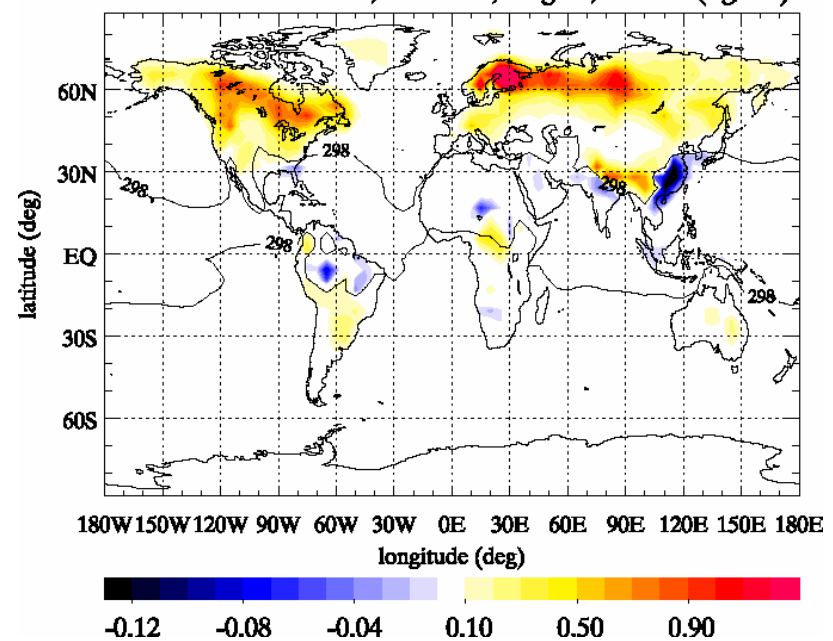

Total SOA difference, case S1.1, August, zonal mean (ug/m3)

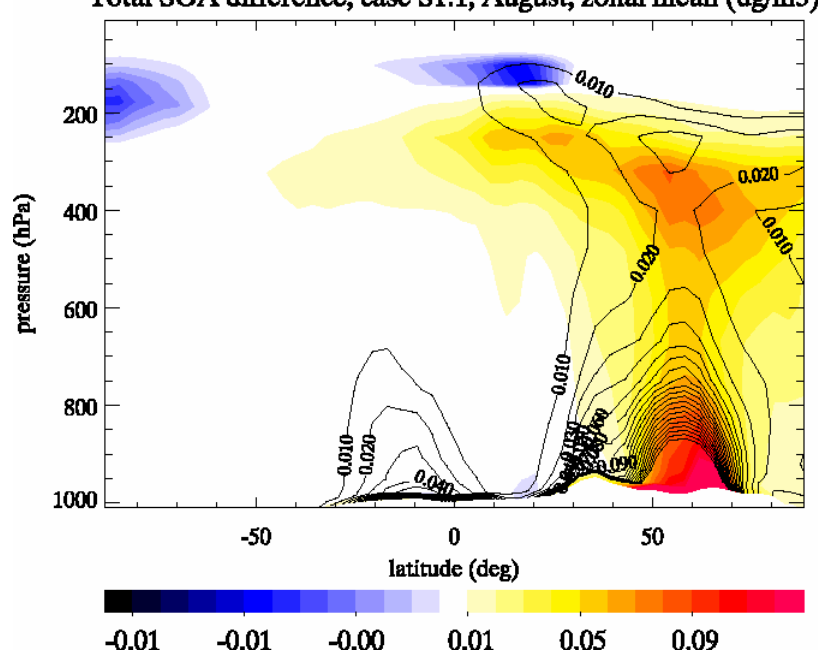

Fig. 6. Calculated differences of the total SOA concentrations in $\mu \mathrm{g} \mathrm{m}^{-3}$ (sum of biogenic and anthropogenic) with increased enthalpy of vaporization $\Delta H$ (case S1.1) compared to the reference case S1 for August, both for surface (left panel) and zonal mean (right panel). Red means increased SOA concentration with increased enthalpy of vaporization and blue means decreased SOA concentration with increased enthalpy of vaporization. The contours in the surface plate show the area with air temperature equal to $298 \mathrm{~K}$ and those in the zonal mean plate show the SOA concentration of the case S1. Note the different scaling between the positive and negative values.

shown in Fig. 6. In general, higher SOA concentrations with decreasing temperature are calculated in S1.1 than in the reference case, since the partitioning coefficient increases faster in S1.1 with decreasing temperature. Near the surface, in areas where temperatures are higher than $298 \mathrm{~K}$ the aerosol concentration decreases, as expected from Eq. (18). At temperatures lower than $298 \mathrm{~K}$, the partitioning coefficient decreases faster with increasing temperature when the enthalpy of vaporization is higher than the base case, while when the temperature is higher than $298 \mathrm{~K}$ the trend is opposite. The enhancement of the total aerosol yield (Fig. 6) due to the temperature dependence of $K_{p}$ displaces the geographical location of the secondary maximum of aerosol mixing ratios towards lower levels (lower altitudes) i.e. at higher temperatures. This reveals the importance of accurate knowledge of the temperature dependence of $K_{p}$ and thus of the physicochemical parameters of the condensable compounds. The chemical structure and chemical fate of the low vapour pressure products seem to be also very critical for the SOA simulations. Indeed, the calculated differences that occur when taking into account the further oxidation of the primary condensable products (case S1.3) compared to our reference case can be seen in Fig. 7. Near the surface, taking into account the formation of the secondary condensable products, leads to higher SOA concentrations compared to the reference case. This happens because the second generation products are assumed to have higher partitioning coefficients, resulting in higher aerosol yield. On the contrary, in the upper troposphere a decrease of SOA concentration is calculated because of the condensation of the gas-phase condensable species at lower altitudes.

\section{Comparison with measurements}

Comparison of the model results with observations may identify which simulations and assumptions are more realistic.

Unfortunately, the measurements of carbonaceous aerosols around the world are sparse. Additionally, the comparison of model results with measurements cannot be done with all data available, since the model grid represents the mean concentration of rather large areas. In this respect, it is not appropriate to compare the model with the measurements from a site with high local influence, i.e. the centre of a city. Therefore, we selected the measurements that could be representative of relatively large rural, remote and marine areas. Another uncertainty in the model evaluation with the observations comes from the conversion of organic aerosol mass (OA) that is simulated by the model to the organic carbon (OC) content of the aerosol measured in the field. To convert the model calculated OA concentration to $\mathrm{OC}$ concentration we use the global mean ratio $\mathrm{OA} / \mathrm{OC}=1.3$ suggested by Liousse et al. (1996). Note that this ratio is expected to vary spatially but this variation has been neglected here. This is not the case though for black carbon, where the comparison with measurements is direct.

Figure 8 compares BC measurements with our model results, including the results from Liousse et al. (1996) and Chung and Seinfeld (2002) where available. No specific trend in all three different models is observed from this figure. All models seem to capture the order of magnitude of the BC data. Note that the scale in this figure is logarithmic and unfortunately no statistically significant correlation can be derived from this comparison. 
Total SOA difference, case S1.3, August, surface (ug/m3)

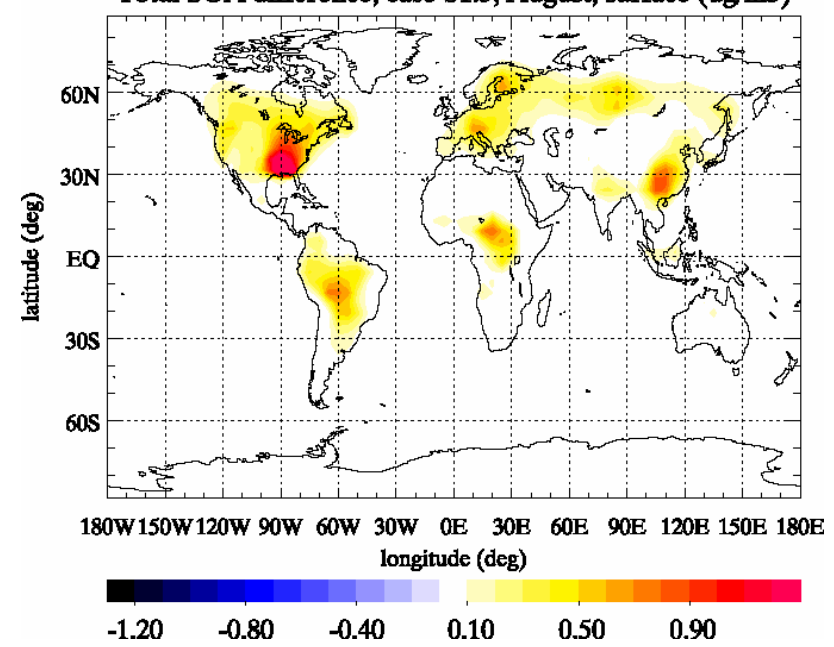

Total SOA difference, case S1.3, August, zonal mean (ug/m3)

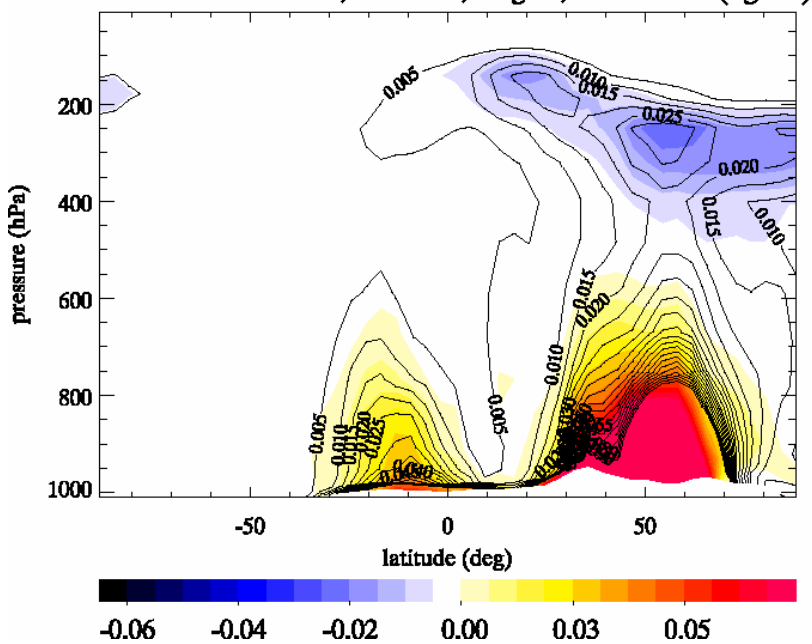

Fig. 7. Calculated differences of the total SOA concentrations in $\mu \mathrm{g} \mathrm{m}^{-3}$ (sum of biogenic and anthropogenic) when taking into account the oxidation of the primary oxidation products of the SOA precursor VOC (case S1.3) compared to the reference case S1 for August, both for surface (left panel) and zonal mean (right panel) case. Red means increased SOA concentration when we take into account the oxidation of the primary products and blue means decreased SOA concentration when we take into account the oxidation of the primary products. The contours in the zonal mean plates show the SOA concentration of the case S1.

In the case of organic aerosols (Fig. 9a) the observations are sparser. Comparison of model results to observations, where available, shows a better agreement for the upper budget estimates than for the lower ones. All model simulations (range of results depicted as vertical bars in Fig. 9a), and particularly S1, underestimate OC concentrations below $1 \mu \mathrm{g} \mathrm{m}^{-3}$ i.e. over relatively clean rural and marine areas. Note also that at OC levels below $1 \mu \mathrm{g} \mathrm{m}^{-3}$, measurements are subject to high uncertainties. With the actual knowledge, it is difficult to attribute the discrepancy between model results and observations to the primary or the secondary carbon, since it is hard to separate the secondary from the primary carbon in the field measurements. To analyse the differences between calculated and observed OA concentrations, the rural, marine (coastal) and open ocean data have been distinguished in Fig. 9a with different colours. The areas where the model predicts too low OC concentrations are mainly remote marine areas, suggesting either that the model might have very high removal of organic aerosols or that condensation on sea-salt aerosol (not taken into account in our study) might be of importance for these areas or that an oceanic source of organic particles is missing. Indeed, neglecting the hydrophobic to hydrophilic conversion of primary organic particles the removal of the aerosols from the atmosphere is reduced and the corresponding comparison between calculated and observed organic aerosol data is improved (case S1.8, Fig. 9b). For all simulations the least square correlation coefficient $r^{2}$ ranges between 0.45 and $0.53(n=40)$ with slopes from 0.69 to 0.96 (case S4 simulates best the measurements). Case S1.6 (with double primary carbonaceous aerosol emissions) overestimates the high rural data since the corresponding slope is 1.26. The results of Chung and Seinfeld (2002) also seem to generally underpredict the measurements in remote marine areas, while Liousse et al. (1996) results, even the few available numbers, agree relatively well with the measurements (Fig. 9a). Both these earlier studies use an almost two times higher source of POA than in our study.

An interesting feature one can raise is that since in our model we have similar treatment of POA particles and BC particles, one would expect that their comparison with measurements would follow the same pattern. This is not the case, since the model calculates the $\mathrm{BC}$ carbon measurements in remote marine areas much closer to the measured ones than for OA. This might be an indication that there are local sources of POA or that the main problem in the OA calculation is not the primary fraction, but the secondary one. Figure $9 \mathrm{c}$ presents the SOA/OA ratio as a function of the OA observations and supports that indeed SOA can be more than $50 \%$ of the total organic aerosol in many cases and up to $90 \%$. Thus, discrepancies between modelled and observed organic aerosols can be partially due either to high SOA removal by wet deposition or too low SOA chemical production, or both. Improved knowledge of the chemical formation and properties of SOA is needed to reduce these discrepancies. 


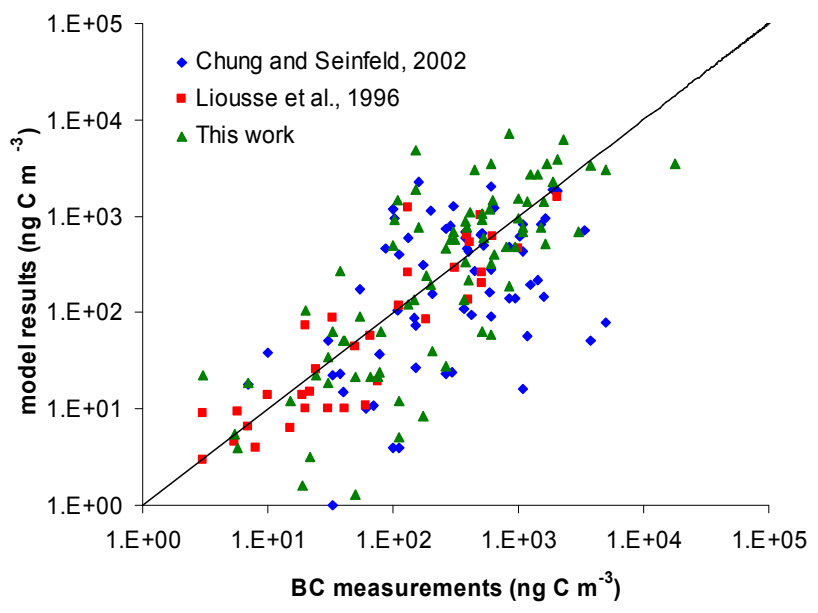

Fig. 8. Comparison of black carbon measurements with our model results and other models (Liousse et al., 1996; Chung and Seinfeld, 2002). The continuous line shows the 1:1 relationship between model results and measurements. Measurements taken from: Andreae et al., 1984; Dzubay et al., 1984; Ohta and Okita, 1984; Cachier et al., 1986; 1989; 1990; 1994; Japar et al., 1986; Wolff et al., 1986; Hansen et al., 1988; 1991; Noone and Clarke, 1988; Clarke, 1989; Mukai et al., 1990; Heintzenberg and Bigg, 1990; Jennings and O'Dowd, 1990; Hopper et al., 1991; Yaaqub et al., 1991; Jennings et al., 1993; Polissar, 1993; Raunemaa et al., 1993; 1994; Chow et al., 1994; Heintzenberg and Leck, 1994; Parungo et al., 1994; Bodhaine, 1995; Berner et al., 1996; Liousse et al., 1996; Lowe et al., 1996; Pio et al., 1996; Smith et al., 1996; Bahrmann and Saxena, 1998; Wolff and Cachier, 1998; Bizjak et al., 1999; Castro et al., 1999; Chýlek et al., 1999; Hitzenberger et al., 1999; Zappoli et al., 1999; Kaneyasu and Murayama, 2000; Kim et al., 2000; Novakov et al., 2000; Puxbaum et al., 2000.

\section{Conclusions}

A global 3-dimensional chemistry/transport model has been extended to simulate the temporal and spatial distribution of carbonaceous aerosols in the global troposphere with focus on the secondary organic aerosol formation. It also considers the conversion of primary carbonaceous aerosols from hydrophobic to hydrophilic. The $\alpha$ - and $\beta$-pinene, toluene and xylene have been used to represent the biogenic and anthropogenic VOC forming SOA precursors, respectively. The chemical lumping of SOA precursors and their oxidation products is by far the largest source of uncertainties in SOA modelling that requires systematic evaluation in the future on the basis of targeted experiments and should rely on deep understanding of chemical pathways that lead to the SOA formation. The model sensitivity to the other input parameters and to the model assumptions has been carefully investigated, since the missing knowledge on SOA formation and properties inhibits an accurate SOA budget estimate.

The global annual production of SOA has been calculated to vary from 2.5 to $44.0 \mathrm{Tg}^{-1}$ for the biogenically produced SOA and from 0.05 to $2.62 \mathrm{Tg}^{-1}$ for the anthro- pogenic SOA. However these values have to be considered as a lower limit, since SOA formation from $\mathrm{NO}_{3}$ reactions with all VOC and from $\mathrm{OH}$ oxidation with biogenic $\mathrm{VOC}$ has been neglected, as well as condensation on nitrate, sea-salt and dust pre-existing particles and aerosol water. The SOA distribution maximises at the surface, close to the source regions of the precursor VOC, and also gives lower intensity maximum in the upper troposphere, close to the tropopause region where temperatures are very low and partitioning coefficients very high.

According to our sensitivity analysis, the most critical factors of uncertainty studied here for the SOA budget turn out to be the potential irreversible sticking of semi-volatile compounds onto the aerosol phase, the aerosol mass on which the gas-phase of the semi-volatile compounds can condense and the temperature dependence of the partitioning coefficient that is linked to the enthalpy of vaporization of the semi-volatile products. Thus the fate of semi- volatile compounds once condensed on the aerosol requests investigation by chamber and field experiments with regard to heterogeneous reactions or physical processes that might result to low volatility products and thus to irreversible sticking of organic matter on the aerosol phase. The enthalpy of vaporization of the condensable species is a highly uncertain parameter that deserves to be experimentally studied in detail since it affects both the chemical production and the spatial distribution of the SOA and displaces the upper tropospheric maximum in SOA mass in lower altitudes for compounds with higher $\Delta H$ compared to species with lower $\Delta H$. The ability of aerosol other than carbonaceous to act as absorbing surfaces for SOA condensation has to be also evaluated.

Another major point of uncertainty is the deposition processes, since the mass and size distributions and the solubility of the organic compounds are needed in order to parameterise correctly these procedures. In order to reduce the errors introduced by these latter uncertainties, a more sophisticated model is needed, considering the evolution of both the physicochemical behaviour and the size distribution of the aerosols in addition to the above analysed factors.

Acknowledgements. We would like to thank F. J. Dentener and M. Krol for helpful comments concerning the TM3 model, P. J. Crutzen, N. Mihalopoulos and S. N. Pandis for constructive discussions, S. N. Pandis for communication of data prior publication, J. H. Seinfeld for pertinent comments during and after the Joint IGAC/CACGP 2002 International Symposium and Serena Chung and the two anonymous reviewers for their suggestions that helped improving the presentation of our results. This work has been supported by the EU project PHOENICS (EVK2-CT-2001-00098). 

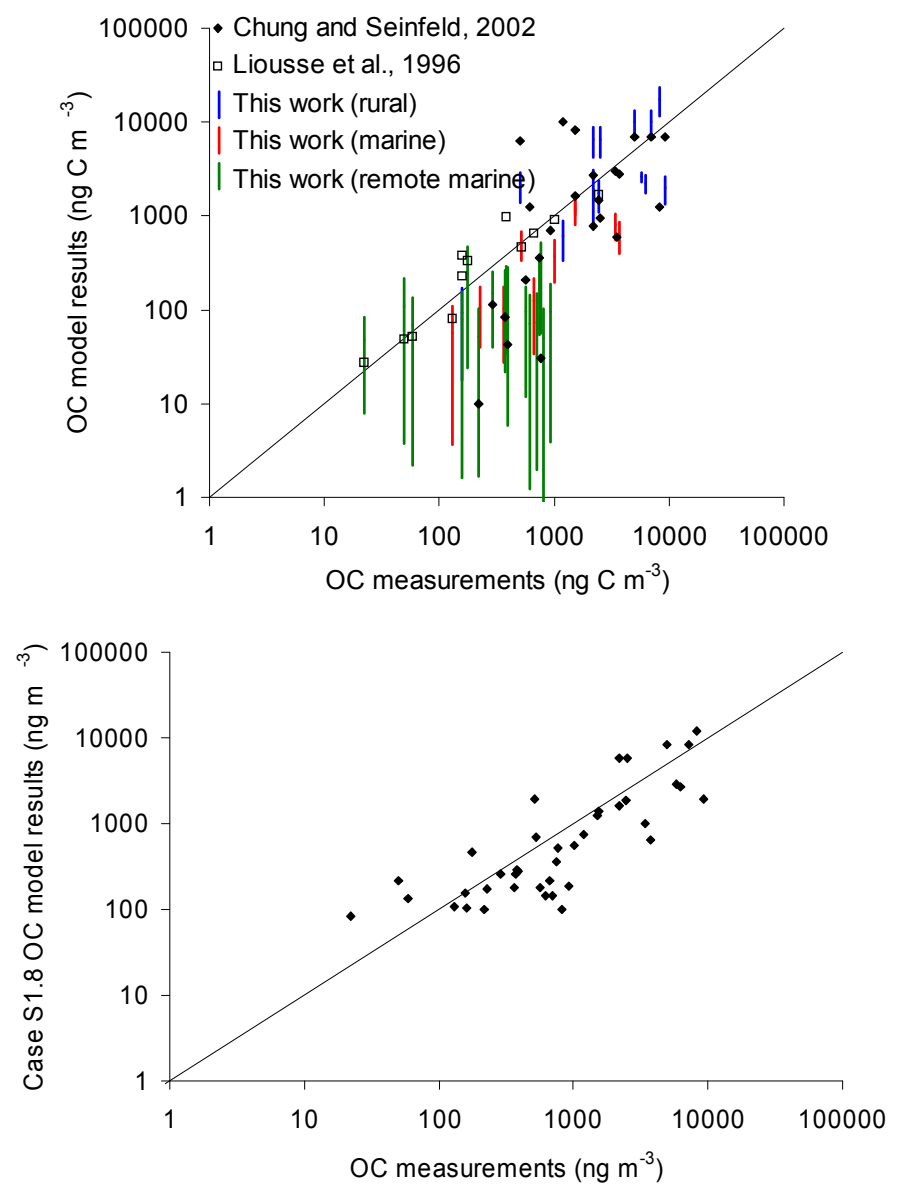

(a)

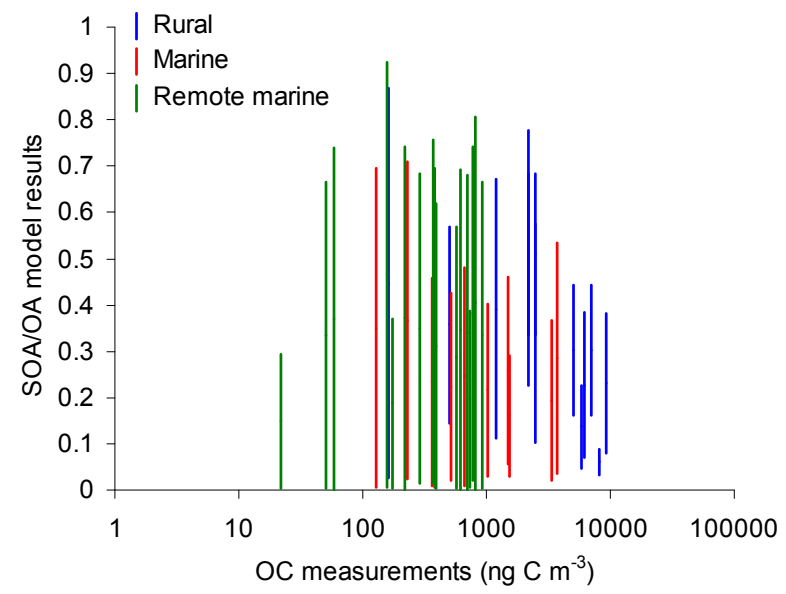

(b)

(c)

Fig. 9. (a) Comparison of organic carbon measurements with our model results. The continuous line shows the 1:1 relationship between model results and measurements and the vertical bars represent the range of all studied cases. The model results by Liousse et al. (1996) and Chung and Seinfeld (2002) are depicted by open squares and closed diamonds, respectively. Measurements taken from: Hidy et al., 1974; Hoffmann and Duce, 1974; 1977; Ketseridis et al., 1976; Chesselet et al., 1981; Andreae, 1982; 1983; Andreae et al., 1984; Dzubay et al., 1984; Ohta and Okita, 1984; Cachier et al., 1986; 1989; 1990; 1994; Japar et al., 1986; Wolff et al., 1986; Clarke, 1989; Mukai et al., 1990; Novakov and Penner, 1993; Chow et al., 1994; Liousse et al., 1996; Novakov et al., 1997; Castro et al., 1999; Molnár et al., 1999; Zappoli et al., 1999; Kim et al., 2000; Puxbaum et al., 2000. (b) Comparison of OC calculations in case S1.8 with observations. (c) SOA to OA ratio (dimensionless) as calculated by the model for all studied cases as a function of the OC measurements. 


\section{References}

Andersson-Sköld, Y. and Simpson, D.: Secondary organic aerosol formation in northern Europe: a model study, J. Geophys. Res., 106, 7357-7374, 2001.

Andreae, M. O., Andreae, T. W., Ferek, R. J., and Raemdonck, H.: Long-range transport of soot carbon in the marine atmosphere, Sci. Tot. Environ., 36, 73-80, 1984.

Andreae, M. O.: Marine aerosol chemistry at Cape Grim, Tasmania, and Townsville, Queensland, J. Geophys. Res., 87, 8875-8885, 1982.

Andreae, M. O.: Soot carbon and excess fine potassium: long-range transport of combustion- derived aerosols, Science, 220, 11481151, 1983.

Andreae, M. O. and Crutzen, P. J.: Atmospheric aerosols: biogeochemical sources and role in atmospheric chemistry, Science, 276, 1052-1058, 1997.

Artaxo, P., Maenhaut, W., Storms, H., and Grieken, R. V.: Aerosol characteristics and sources for the Amazon basin during the wet season, J. Geophys. Res., 95, 16 971-16 986, 1990.

Artaxo, P., Storms, H., Bruynseels, F., Grieken, R. V., and Maenhaut, W.: Composition and Sources of Aerosols from the Amazon Basin, J. Geophys. Res., 93, 1605-1615, 1988.

Atkins, P. W.: Physical chemistry, 4th ed., Oxford University Press, Oxford, 143, 1990.

Atkinson, R.: Gas-phase tropospheric chemistry of organic compounds, J. Phys. Chem. Ref. Data, Monogr., 2, 1-216, 1994.

Atkinson, R.: Gas-phase tropospheric chemistry of volatile organic compounds: 1. Alkanes and alkenes, J. Phys. Chem. Ref. Data, 26, 215-290, 1997.

Bahrmann, C. P. and Saxena, V. K.: Influence of air mass history on black carbon concentrations and regional climate forcing in southeastern United States, J. Geophys. Res. 103, 23 153-23 161, 1998.

Barrie, L. A., Yi, Y., Leaitch, W. R., Lohmann, U., Kasibhatla, P., Roelofs, G.-J., Wilson. J., McGovern, F., Benkovitz, C., Melieres, M. A., Law, K., Prospero, J., Kritz, M., Bergmann, D., Bridgeman, C., Chin, M., Christensen, J., Easter, R., Feichter, J., Land, C., Jeuken, A., and Kjellstrom, E.: A comparison of largescale atmospheric sulphate aerosol models (COSAM): Overview and highlights. Tellus, 53B, 615-645, 2001.

Berner, A., Sidla, S., Galambos, Z., Kruisz, C., Hitzenberger, R., ten Brink, H. M., and Kos, G. P. A.: Modal character of atmospheric black carbon size distributions, J. Geophys. Res. 101, 1955919565, 1996.

Bizjak, M., Turšic, J., Lešnjak, M., and Cegnar, T.: Aerosol black carbon and ozone measurements at Mt. Krvavec EMEP/GAW station, Slovenia, Atmos. Environ. 33, 2783-2787, 1999.

Bodhaine, B. A.: Aerosol absorption measurements at Barrow, Mauna Loa and the south pole, J. Geophys. Res. 100, 8967-8975, 1995.

Bowman, F. M. and Karamalegos, A. M.: Estimated effects of composition on secondary organic aerosol mass concentrations, Environ. Sci. Technol., 36, 2701-2707, 2002.

Cachier, H., Brémond, M. P., and Buat-Ménard, P.: Organic and black carbon aerosols over marine regions of the northern hemisphere, in Proceedings of the International Conference on Global and Regional Environmental Atmospheric Chemistry, edited by: Newman, L., Wang, W., and Kiang, C. S., Department of Energy, Brookhaven National Laboratory, Upton, New York, 249-261,
1990.

Cachier, H., Brémond, M.-P., and Buat-Ménard, P.: Determination of atmospheric soot carbon with a simple thermal method, Tellus 41B, 379-390, 1989.

Cachier, H., Buat-Ménard, P., Fontugne, M., and Chesselet, R.: Long-range transport of continentally-derived particulate carbon in the marine atmosphere: evidence from stable carbon isotope studies, Tellus 38B, 161-177, 1986.

Cachier, H., Liousse, C., Cachier, B., Ardouin, B., Polian, G., Kaza, V., and Hansen, A. D. A.: Black carbon aerosol at the remote site of Amsterdam island, paper presented at the Fifth International Conference on Carbonaceous Aerosols, US Department of Energy, Berkeley, California, 23-26 August, 1994.

Calogirou, A., Larsen, B. R., and Kotzias, D.: Gas-phase terpene oxidation products: a review, Atmos. Environ., 33, 1423-1439, 1999.

Castro, L. M., Pio, C. A., Harrison, R. M., and Smith, D. J. T.: Carbonaceous aerosol in urban and rural European atmospheres: estimation of secondary carbon concentrations, Atmos. Environ., 33, 2771-2781, 1999.

Chesselet, R., Fontugne, M., Buat-Ménard, P., Ezat, U., and Lambert, C. E.: The origin of particulate organic carbon in the marine atmosphere as indicated by its stable carbon isotopic composition, Geophys. Res. Lett. 8, 345-348, 1981.

Chow, J. C., Watson, J. G., Fujita, E. M., Lu, Z., and Lawson, D. R.: Temporal and spatial variations of $\mathrm{PM}_{2.5}$ and $\mathrm{PM}_{10}$ aerosol in the southern California air quality study, Atmos. Environ., 28, 2061-2080, 1994.

Christoffersen, T. S., Hjorth, J., Horie, O., Jensen, N. R., Kotzias, D., Molander, L. L., Neeb, P., Ruppert, L., Winterhalter, R., Virkkula, A., Wirtz, K., and Larsen, B. R.: Cis-pinic acid, a possible precursor for organic aerosol formation from ozonolysis of $\alpha$-pinene, Atmos. Environ. 32, 1657-1661, 1998.

Chung, S. H. and Seinfeld, J. H.: Global distribution and climate forcing of carbonaceous aerosols, J. Geophys. Res., 107, 4407, doi:10.1029/2001JD001397, 2002.

Chýlek, P., Kou, L., Johnson, B., Boudala, F., and Lesins, G.: Black carbon concentrations in precipitation and near surface air in and near Halifax, Nova Scotia, Atmos. Environ., 33, 2269-2277, 1999.

Clarke, A. D.: Aerosol light absorption by soot in remote environments, Aeros. Sci. Technol., 10, 161-171, 1989.

Cocker III, D. R., Clegg, S. L., Flagan, R. C., and Seinfeld, J. H.: The effect of water on gas-particle partitioning of secondary organic aerosol. Part I: $\alpha$-pinene/ozone system, Atmos. Environ., 35, 6049-6072, 2001a.

Cocker III, D. R., Mader, B. T., Kalberer, M., Flagan, R. C., and Seinfeld, J. H.: The effect of water on gas-particle partitioning of secondary organic aerosol. Part II: m-xylene and 1,3,5trimethylbenzene photooxidation systems., Atmos. Environ., 35, 6073-6085, 2001b.

Cooke, W. F., Liousse, C., Cachier, H., and Feichter, J.: Construction of a $1^{\circ} \times 1^{\circ}$ fossil fuel emission data set for carbonaceous aerosol and implementation and radiative impact in the ECHAM4 model, J. Geophys. Res., 104, 22 137-22 162, 1999.

Decesari, S., Facchini, M. C., Matta, E., Mircea, M., Fuzzi, S., Chughtai, A. R., and Smith D. M.: Water soluble organic compounds formed by oxidation of soot, Atmos. Environ. 36, 1827 $1832,2002$. 
Dentener, F. J. and Crutzen, P. J.: Reaction of $\mathrm{N}_{2} \mathrm{O}_{5}$ on tropospheric aerosols: impact on the global distributions of $\mathrm{NO}_{\mathrm{x}}, \mathrm{O}_{3}$ and $\mathrm{OH}$, J. Geophys. Res., 98, 7149-7163, 1993.

Dentener, F. J., Feichter, J., and Jeuken, A.: Simulation of the transport of $\mathrm{Rn}^{222}$ using on-line and off-line global models at different horizontal resolutions: a detailed comparison with measurements, Tellus, 51B, 573-602, 1999.

Derwent, R. G., Collins, W. J., Jenkin, M. E., Johnson, C. E., and Stevenson, D. S.: The global distribution of secondary organic particulate matter in a 3-D lagrangian chemistry transport model, J. Atm. Chem., 44, 57-95, 2003.

Dzubay, T. G., Stevens, R. K., and Haagenson, P. L.: Composition and origins of aerosol at a forested mountain in Soviet Georgia, Environ. Sci. Technol., 18, 873-883, 1984.

Facchini, M. C., Fuzzi, S., Zappoli, S., Andracchio, A., Gelencsér, A., Kiss, G., Krivácsy, Z., Mészáros, E., Hansson, H.-C., Alsberg, T., and Zebühr, Y.: Partitioning of the organic aerosol component between fog droplets and interstitial air, J. Geophys. Res., 104, 26 821-26 832, 1999.

Forstner, H. J. L., Flagan, R. C., and Seinfeld, J. H.: Secondary organic aerosol from the photooxidation of aromatic hydrocarbons: molecular composition, Environ. Sci. Technol., 31, 1345-1358, 1997.

Fuzzi, S., Decesari, S., Facchini, F. C., Matta, E., Mircea, M., and Tagliavini, E.: A simplified model of the water soluble organic component of atmospheric aerosols, Geophys. Res. Lett., 28, 4079-4082, 2001.

Ganzeveld, L. and Lelieveld, J.: Dry deposition parameterization in a chemistry general circulation model and its influence on the distribution of reactive trace gases, J. Geophys. Res., 100, 20 999-21 012, 1995.

Gery, M. W., Whitten, G. Z., Killus, J. P., and Dodge, M. C.: A photochemical kinetics mechanism for urban and regional scale computer modeling, J. Geophys. Res., 94, 12 925-12 956, 1989.

Gibson, R., Kallberg, P., and Uppala, S.: The ECMWF re-analysis (ERA) project, ECMWF newsletter, 73, 7-17, 1997.

Griffin, R. J., Cocker III, D. R., Flagan, R. C., and Seinfeld, J. H.: Organic aerosol formation from oxidation of biogenic hydrocarbons, J. Geophys. Res., 104, 3555-3567, 1999a.

Griffin, R. J., Cocker III, D. R., Seinfeld, J. H., and Dabdub, D.: Estimate of global atmospheric organic aerosol from oxidation of biogenic hydrocarbons, Geophys. Res. Lett., 26, 2721-2724, $1999 b$.

Guenther, A., Hewitt, C. N., Erickson, D., Fall, R., Geron, C., Graedel, T., Harley, P., Klinger, L., Lerdau, M., McKay, W. A., Pierce, T., Scholes, B., Steinbrecher, R., Tallamraju, R., Taylor, J., and Zimmerman, P. A global model of natural volatile organic compound emissions, J. Geophys. Res., 100, 8873-8892, 1995.

Hansen, A. D. A., Bodhaine, B. A., Dutton, E. G., and Schnell, R. C.: Aerosol black carbon measurement at the South Pole: initial results, 1986-1987, Geophys. Res. Lett., 15, 19 193-19 196, 1988.

Hansen, A. D. A., Kapustin, V. N., and Polissar, A. D.: Measurements of airborne carbonaceous aerosols in the eastern Arctic, Izv. Acad. Sci. USSR Atmos. Oceanic. Phys. Engl. Transl., 27, 429-433, 1991.

Harrison, R. M. and Yin, J.: Particulate matter in the atmosphere: which particle properties are important for its effects on health?, Sci. Tot. Environ., 249, 85-101, 2000.
Heintzenberg, J. and Bigg, E. K.: Tropospheric transport of trace substances in the southern hemisphere, Tellus, 42B, 355-363, 1990.

Heintzenberg, J. and Leck, C.: Seasonal variation of the atmospheric aerosol near the top of the marine boundary layer over Spitzenberg related to the Arctic sulfur cycle, Tellus, 46B, 5267, 1994

Hidy, G. M., Mueller, P. K., Wang, H. H., Karney, J., Twiss, S., Imada, M., and Alcocer, A.: Observations of aerosols over southern California coastal waters, J. Appl. Meteorol., 13, 96-107, 1974.

Hitzenberger, R., Berner, A., Giebl, H., Kromp, R., Larson, S. M., Rouc, A., Koch, A., Marischka, S., and Puxbaum, H.: Contribution of carbonaceous material to cloud condensation nuclei concentrations in European background (Mt. Sonnblick) and urban (Vienna) aerosols, Atmos. Environ., 33, 2647-2659, 1999.

Hjorth, J., Wirtz, K., Moortgat, G., Ljungström, E., Becker, K. H., and Hayman, G.: 1st annual report on EU project on "Degradation mechanisms of biogenic VOCs - BIOVOC", 1996.

Hoffmann, E. J. and Duce, R. A.: Organic carbon in marine atmospheric particulate matter: Concentration and particle size distribution, Geophys. Res. Lett., 4, 449-452, 1977.

Hoffmann, E. J., and Duce, R. A.: The organic carbon content of marine aerosols collected on Bermuda, J. Geophys. Res., 79, 4474-4477, 1974.

Hoffmann, T., Odum, J. R., Bowman, F., Collins, D., Klockow, D., Flagan, R. C., and Seinfeld, J. H.: Formation of organic aerosols from the oxidation of biogenic hydrocarbons, J. Atmos. Chem., 26, 189-222, 1997.

Hopper, J. F., Barrie, L. A., Trivett, N. B., and Worthy, D. J.: Continuuous measurements of black carbon and related species at Alert, Canada, paper presented to the Fourth International Conference on Carbonaceous Aerosols, Austrian Federal Ministries of Environment, and Science and Technology, Vienna, 3-5 April, 1991.

Houweling, S., Dentener, F., and Lelieveld, J.: The impact of nonmethane hydrocarbon compounds on tropospheric chemistry, J. Geophys. Res., 103, 10 673-10 696, 1998.

IPCC (Intergovernmental Panel for Climate Change): Summary for policy makers, A report of working group I of the IPCC, http: //www.ipcc.ch, 2001.

Jacob, D. J., Prather, M. J., Rasch, P. J., Shia, R.L., Balkanski, Y. J., Beagley, S. R., Bergmann, D. J., Blackshear, W. T., Brown, M., Chiba, M., Chipperfield, M. P., de Grandpré, J., Dignon, J. E., Feichter, J., Genthon, C., Grose, W. L., Kasibhatla, P. S., Köhler, I., Kritz, M. A., Law, K., Penner, J. E., Ramonet, M., Reeves, C. E., Rotman, D. A., Stockwell, D. Z., Van Velthoven, P. F. J., Verver, G., Wild, O., Yang, H., and Zimmermann, P.: Evaluation and intercomparison of global atmospheric transport models using ${ }^{222} \mathrm{Rn}$ and other short-lived tracers, J. Geophys. Res., 102, 5953-5970, 1997.

Japar, S. M., Brachaczek, W. W., Gorse Jr., R. A., Norbeck, J. M., and Pierson, W. R.: The contribution of elemental carbon to the optical properties of rural atmospheric aerosols, Atmos. Environ., 20, 1281-1289, 1986.

Jennings, S. G., McGovern, F. M., and Cooke, W. F.: Carbon mass concentration measurements at Mace Head, on the west coast of Ireland, Atmos. Environ., 27A, 1229-1239, 1993.

Jennings, S. G., and O'Dowd, C. D.: Volatility of aerosol at Mace 
head on the west coast of Ireland, J. Geophys. Res., 95, 13937$13948,1990$.

Jeuken, A., Veefkind, J. P., Dentener, F., Metzger, S., and Gonzalez, C. R.: Simulation of the aerosol optical depth over Europe for August 1997 and a comparison with observations, J. Geophys. Res., 106, 28 295-28 311, 2001.

Jones, A. P.: Indoor air quality and health, Atmos. Environ., 33, 4535-4564, 1999.

Kanakidou, M., Tsigaridis, K., Dentener, F. J., and Crutzen, P. J.: Human-activity-enhanced formation of organic aerosols by biogenic hydrocarbon oxidation, J. Geophys. Res., 105, 9243-9254, 2000.

Kaneyasu, N. and Murayama, S.: High concentrations of black carbon over middle latitudes in the North Pacific Ocean, J. Geophys. Res., 105, 19881-19890, 2000.

Ketseridis, G., Hahn, J., Jaenicke, R., and Junge, C.: The organic constituents of atmospheric particulate matter, Atmos. Environ., 10, 603-610, 1976.

Kim, Y. P., Moon, K.-C., and Lee, J. H.: Organic and elemental carbon in fine particles at Kosan, Korea, Atmos. Environ., 34, 3309-3317, 2000.

Kwok, E. S. C. and Atkinson, R.: Estimation of hydroxyl radical reaction rate constants for gas-phase organic compounds using a structure-reactivity relationship: an update, Atmos. Environ., 29, 1685-1695, 1995.

Liousse, C., Penner, J. E., Chuang, C., Walton, J. J., Eddleman, H., and Cachier, H.: A global three-dimensional model study of carbonaceous aerosols, J. Geophys. Res., 101, 19411-19432, 1996.

Lowe, J. A., Smith, M. H., Davison, B. M., Benson, S. E., Hill, M. K., O'Dowd, C. D., Harrison, R. M., and Hewitt, C. N.: Physicochemical properties of atmospheric aerosol at south Uist, Atmos. Environ. 30, 3765-3776, 1996.

Martínez, E., Cabañas, B., Aranda, A., and Martín, P.: Kinetics of the reactions of $\mathrm{NO}_{3}$ radical with selected monoterpenes: a temperature dependence study, Environ. Sci. Technol., 32, 37303734, 1998.

Molnár, A., Mészáros, E., Hansson, H. C., Karlsson, H., Gelencsér, A., Kiss, G., and Kriváczy, Z.: The importance of organic and elemental carbon in the fine atmospheric aerosol particles, Atmos. Environ., 33, 2745-2750, 1999.

Mukai, H., Ambe, Y., Shibata, K., Muku, T., Takeshita, K., Fukuma, T., Takahashi, J., and Mizota, S.: Long-terp variation of chemical composition of atmospheric aerosol on the Oki islands in the sea of Japan, Atmos. Environ., 24A, 1379-1390, 1990.

Noone, K. J. and Clarke, A. D.: Soot scavenging measurements in Arctic snowfall, Atmos. Environ., 22, 2773-2778, 1988.

Novakov, T., Bates, T. S., and Quinn, P. K.: Shipboard measurements of concentrations and properties of carbonaceous aerosols during ACE-2, Tellus, 52B, 228-238, 2000.

Novakov, T., Corrigan, C. E., Penner, J. E., Chuang, C. C., Rosario, O., and Mayol Bracero, O. L.: Organic aerosols in the Caribbean trade winds: a natural source?, J. Geophys. Res., 102, $21307-$ $21313,1997$.

Novakov, T. and Corrigan, C. E.: Cloud condensation nucleus activity of the organic component of biomass smoke particles, Geophys. Res. Lett., 23, 2141-2144, 1996.

Novakov, T., and Penner, J. E.: Large contribution of organic aerosols to cloud-condensation- nuclei concentrations, Nature,
365, 823-826, 1993.

Odum, J. R., Hoffmann, T., Bowman, F., Collins, D., Flagan, R. C., and Seinfeld, J. H.: Gas/particle partitioning and secondary organic aerosol yields, Environ. Sci. Technol., 30, 2580-2585, 1996.

Odum, J. R., Jungkamp, T. P. W., Griffin, R. J., Flagan, R. C., and Seinfeld, J. H.: The atmospheric aerosol-forming potential of whole gasoline vapor, Science, 276, 96-99, 1997.

Ohta, S. and Okita, T.: Measurements of particulate carbon in urban and marine air in Japanese areas, Atmos. Environ., 18, 24392445, 1984.

Olivier, J. G. J., Bouwman, A. F., Van der Maas, C. W. M., Berdowski, J. J. M, Veldt, C. Bloos, J. P. J., Visschedijk, A. J. H., Zandveld, P. Y. J., and Haverlag, J. L.: Description of EDGAR Version 2.0. A set of global emission inventories of greenhouse gases and ozone-depleting substances for all anthropogenic and most natural sources on a per country basis and on $1^{\circ} \times 1^{\circ}$ grid. RIVM/TNO report, December 1996, RIVM, Bilthoven, RIVM report no. 771060002 (TNO MEP report no. R96/119), 1996.

Pandis, S. N., Harley, R. A., Cass G. R., and Seinfeld, J. H.: Secondary organic aerosol formation and transport, Atmos. Environ., 26A, 2269-2282, 1992.

Pankow, J. F.: An absorption model of gas/particle partitioning of organic compounds in the atmosphere, Atmos. Environ., 28, 185-188, 1994a.

Pankow, J. F.: An absorption model of the gas/aerosol partitioning involved in the formation of secondary organic aerosol, Atmos. Environ., 28, 189-193, 1994b.

Parungo, F., Nagamoto, C., Zhou, M.-Y., Hansen, A. D. A., and Harris, J.: Aeolian transport of aerosol black carbon from China to the ocean, Atmos. Environ., 28, 3251-3260, 1994.

Parungo, F., Nagamoto, C., Zhou, M.-Y., Hansen, A. D. A., and Harris, J.: Aeolian transport of aerosol black carbon from China to the ocean, Atmos. Environ., 28, 3251-3260, 1994.

Pio, C. A., Castro, L. M., Cerqueira, M. A., Santos, I. M., Belchior, F., and Salgueiro, M. L.: Source assesment of particulate air pollutants measured at the soutwest European coast, Atmos. Environ., 30, 3309-3320, 1996.

Polissar, A. V.: Measurements of the soot mass concentration in the north Atlantic, Izv. Acad. Sci. USSR Atmos. Oceanic Phys. Engl. Transl., 29, 66-73, 1993.

Pöschl, U., Letzel, T., Schauer, C., and Niessner, R.: Interaction of ozone and water vapor with spark discharge soot aerosol particles coated with benzo[a]pyrene: $\mathrm{O}_{3}$ and $\mathrm{H}_{2} \mathrm{O}$ adsorption, benzo $[\alpha]$ pyrene degradation, and atmospheric implications, J. Phys. Chem. A, 105, 4029-4041, 2001.

Prausnitz, J. M.: Molecular thermodynamics of fluid-phase equilibria, edited by: Amundson, N. R., Prentice-Hall Inc.: Englewood Cliffs, New Jersey, 229-233, 1969.

Pun, B. K., Wu, S.-Y., Seigneur, C., Seinfeld, J. H., Griffin, R. J., and Pandis, S. N.: Uncertainties in modeling secondary organic aerosols: three dimensional studies in Nashville/western Tennessee, Environ. Sci. Technol., 37, 3647-3661, 2003.

Puxbaum, H., Rendl, J., Allabashi, R., Otter, L., and Scholes, M. C.: Mass balance of the atmospheric aerosol in a South African subtropical savanna (Nylsvley, May 1997), J. Geophys. Res., 105, 20 697-20 706, 2000.

Raunemaa, T., Kuuspalo, K., Alander, T., Tamm, E., Mirme, A., and Laine, V.: Black carbon and aerosol in Boistö island, J. Aerosol 
Sci., 24, S29-S30, 1993.

Raunemaa, T., Kikas, U., and Bernotas, T.: Observation of submicron aerosol, black carbon and visibility degradation in remote area at temperature-range from -24 to 20 -degrees-C, Atmos. Environ., 28, 865-887, 1994.

Sander, R.: Compilation of Henry's law constants for inorganic and organic species of potential importance in environmental chemistry (version 3), http://www.mpch-mainz.mpg.de/ sander/res/ henry.html, 1999.

Saxena, P. and Hildemann, L. M.: Water-soluble organics in atmospheric particles: A critical review of the literature and application of thermodynamics to identify candidate compounds, J. Atmos. Chem., 24, 57-109, 1996.

Seinfeld J. H. and J. F. Pankow: Organic Atmospheric Particulate Material, Annu. Rev. Phys. Chem., 54, 121-140, 2003.

Smith, D. J. T., Harrison, R. M., Luhana, L., Pio, C. A., Castro, L. M., Tariq, M. N., Hayat, S., and Quraishi, T.: Concentrations of particulate airborne polycyclic aromatic hydrocarbons and metals collected in Lahore, Pakistan, Atmos. Environ., 30, 40314040, 1996.

Strader, R., Lurmann, F., and Pandis, S. N.: Evaluation of secondary organic aerosol formation in winter, Atmos. Environ., 33, 48494863, 1999.

Talbot, R. W, Andreae, M. O., Andreae, T. W., and Harriss, R. C.: Regional Aerosol Chemistry of the Amazon Basin During the Dry Season, J. Geophys. Res., 93, 1499-1508, 1988.
Talbot, R. W., Andreae, M. O., Berresheim, H., Artaxo, P., Garstang, M., Harriss, R. C., Beecher, K. M., Li, S. M.: Aerosol chemistry. during the wet season in central Amazonia: the influence of long-range transport, J. Geophys. Res., 95, 16955-16969, 1990.

Wang, Y., Jacob, D. J., Logan, J. A.: Global simulation of tropospheric $\mathrm{O}_{3}-\mathrm{NO}_{\mathrm{x}}$-hydrocarbon chemistry. 3. Origin of tropospheric ozone and effects of nonmethane hydrocarbons, J. Geophys. Res., 103, 10757-10 767, 1998.

Wesely, M. L.: Parameterization of surface resistances to gaseous dry deposition in regional scale numerical models, Atmos. Environ., 23, 1293-1304, 1989.

Wolff, E. W. and Cachier, H.: Concentrations and seasonal cycle of black carbon in aerosol at a coastal Antarctic station, J. Geophys. Res., 103, 11 033-11 041, 1998.

Wolff, G. T., Ruthkosky, M. S., Stroup, D. P., Korsog, P. E., Ferman, M. A., Wendel, G. J., and Stedman, D. H.: Measurements of $\mathrm{SO}_{\mathrm{x}}, \mathrm{NO}_{\mathrm{x}}$ and aerosol species on Bermuda, Atmos. Environ., 20, 1229-1239, 1986.

Yaaqub, R. R., Davies, T. D., Jickells, T. D., and Miller, J. M.: Trace elements in daily collected aerosols at a site in southeast England, Atmos. Environ., 25A, 985-996, 1991.

Zappoli, S., Andracchio, A., Fuzzi, S., Facchini, M.-C., Gelencsér, A., Kiss, G., Krivácsy, Z., Molnár, á., Mészáros, E., Hansson, H.C., Rosman, K., and Zebühr, Y.: Inorganic, organic and macromolecular components of fine aerosol in different areas in Europe in relation to their water solubility, Atmos. Environ., 33, 2733 2743, 1999. 